\title{
Phytoplankton competition during the spring bloom in four plankton functional type models
}

\author{
T. Hashioka ${ }^{1,2,3,5}$, M. Vogt ${ }^{4}$, Y. Yamanaka ${ }^{1,3,5}$, C. Le Quéré ${ }^{2}$, E. T. Buitenhuis ${ }^{2}$, M. N. Aita ${ }^{5}$, S. Alvain ${ }^{6}$, L. Bopp ${ }^{7}$, \\ T. Hirata ${ }^{1}$, I. Lima ${ }^{8}$, S. Sailley ${ }^{8,}$, and S. C. Doney ${ }^{8}$ \\ ${ }^{1}$ Graduate School of Environmental Earth Science, Hokkaido University, Sapporo, Japan \\ ${ }^{2}$ Tyndall Centre for Climate Change Research, School of Environmental Sciences, University of East Anglia, \\ Norwich NR4 7TJ, UK \\ ${ }^{3}$ Core Research for Evolutional Science and Technology, Japan Science and Technology Agency, Tokyo, Japan \\ ${ }^{4}$ Institute for Biogeochemistry and Pollutant Dynamics, CHN 23.2, Universitaetsstrasse 16, 8092 Zürich, Switzerland \\ ${ }^{5}$ Japan Agency for Marine-Earth Science and Technology, Yokohama, Japan \\ ${ }^{6}$ LOG, Univers ité Lille Nord de France, ULCO, CNRS, Wimereux, France \\ ${ }^{7}$ Laboratoire du Climat et de l'Environnement (LSCE), L'Orme des Merisiers Bât. 712, 91191 Gif sur Yvette, France \\ ${ }^{8}$ Department of Marine Chemistry and Geochemistry, Woods Hole Oceanographic Institution, Woods Hole, MA, USA \\ * now at: Plymouth Marine Laboratory, Plymouth, UK
}

Correspondence to: T. Hashioka (hashioka@jamstec.go.jp)

Received: 20 November 2012 - Published in Biogeosciences Discuss.: 13 December 2012

Revised: 27 August 2013 - Accepted: 17 September 2013 - Published: 2 November 2013

\begin{abstract}
We investigated the mechanisms of phytoplankton competition during the spring bloom, one of the most dramatic seasonal events in lower-trophic-level ecosystems, in four state-of-the-art plankton functional type (PFT) models: PISCES, NEMURO, PlankTOM5 and CCSM-BEC. In particular, we investigated the relative importance of different ecophysiological processes on the determination of the community structure, focusing both on the bottom-up and the top-down controls. The models reasonably reproduced the observed global distribution and seasonal variation of phytoplankton biomass. The fraction of diatoms with respect to the total phytoplankton biomass increases with the magnitude of the spring bloom in all models. However, the governing mechanisms differ between models, despite the fact that current PFT models represent ecophysiological processes using the same types of parameterizations. The increasing trend in the percentage of diatoms with increasing bloom magnitude is mainly caused by a stronger nutrient dependence of diatom growth compared to nanophytoplankton (bottom-up control). The difference in the maximum growth rate plays an important role in NEMURO and PlankTOM5 and determines the absolute values of the percentage of diatoms during the bloom. In CCSM-BEC, the light dependency of growth
\end{abstract}

plays an important role in the North Atlantic and the Southern Ocean. The grazing pressure by zooplankton (top-down control), however, strongly contributes to the dominance of diatoms in PISCES and CCSM-BEC. The regional differences in the percentage of diatoms in PlankTOM5 are mainly determined by top-down control. These differences in the mechanisms suggest that the response of marine ecosystems to climate change could significantly differ among models, even if the present-day ecosystem is reproduced to a similar degree of confidence. For further understanding of plankton competition and for the prediction of future change in marine ecosystems, it is important to understand the relative differences in each physiological rate and life history rate in the bottom-up and the top-down controls between PFTs.

\section{Introduction}

In recent decades, marine ecosystem models have been established as an essential tool for the comprehensive understanding of marine ecosystem dynamics and biogeochemical cycles. In addition, demands for modeling are increasing not only for the quantification of the contribution of ma- 
rine ecosystem to the oceanic carbon cycle, but also for the understanding of marine ecosystems themselves, e.g., how different environmental conditions may lead to changes in biodiversity or biome shifts (Denman et al., 2007). As one possible strategy for the representation of marine ecosystems in models, the plankton functional type (PFT) approach has been suggested (Falkowski, 1999; Moore et al., 2004; Le Quéré et al., 2005). PFT models categorize the enormous diversity in plankton species and taxonomy according to their role as functional types in the biogeochemical cycling of important elements such as N, P, C or S, and their biological role (e.g., size class, contribution to primary production, or food-web structure and trophic level).

Coupled with earth system or climate models, PFT models effectively project several significant impacts on marine ecosystems associated with climate change. For example, models suggest that future impacts on marine ecosystems associated with global warming may include (i) changes in the primary and export productions, (ii) changes in the community structure and (iii) changes in plankton seasonality (phenology). Steinacher et al. (2010) compared the results from four different types of PFT models for the period of 2000-2100. In their study, they found regional patterns with decreased primary production in the subtropics, increased primary production in polar latitudes, and decreased global primary production under global warming. Manizza et al. (2010) suggested an increase in the export production between 2005 and 2061 in high latitude oceans using two different types of PFT models. Boyd and Doney (2001) suggested a future increase in the rate of nitrogen fixation in subtropical regions using a PFT model. Bopp et al. (2005) projected a decrease in diatoms in high latitude oceans associated with increased stratification using a PFT model and a global warming scenario. Furthermore, Hashioka and Yamanaka (2007a) suggested an earlier onset of the spring bloom at the end of the 21 st century using a PFT model. Hashioka et al. (2009) also projected regionally specific changes in the magnitude of blooms in the western North Pacific using a PFT model with an eddy-permitting physical model.

While the simulations using PFT models provide valuable information to assess potential impacts of climate change on marine ecosystems, it is essential to understand the characteristics of each model and to identify key processes that control the projected features. Current PFT models are constructed as interplay of many physiological or biogeochemical processes, which are both observed or (theoretically) expected. Thus, there are many resemblances between the basic mechanisms simulated by current PFT models. For instance, several key processes such as phytoplanktonic photosynthesis or grazing by zooplankton can be described using the same type of equations. However, parameter values are significantly different between models because the observed parameter range is usually wide. The differences in the parameter values correspond to the difference in the relative importance of the individual processes in the model.
The MARine Ecosystem Model Intercomparison Project (MAREMIP) was launched in an effort to evaluate the role of functional groups in the whole ecosystem and to identify the key processes. Four PFT models participated in phase 0 of MAREMIP, i.e., PISCES (Aumont et al., 2006), NEMURO (Kishi et al., 2007), PlankTOM5 (Buitenhuis et al., 2010) and CCSM-BEC (Moore et al., 2004). These models have been compared with each other and validated with observational data.

Here, we investigate the mechanisms of phytoplankton competition between diatoms and nanophytoplankton during the spring bloom in high latitude oceans. Diatoms, which form an intense bloom, are major contributors to global carbon fixation. They account for $40 \%$ of total primary production (Nelson et al., 1995; Mann, 1999; Smetacek, 1999; Tréguer and Pondaven, 2000). Therefore, the fraction of diatoms to the total phytoplankton could be an indicator for biogeochemical and ecological status.

In order to understand the mechanisms of phytoplankton competition, we distinguish between bottom-up and topdown control on biomass. In a system dominated by bottomup control, the phytoplankton biomass and compositions are primarily controlled by phytoplankton production according to environmental conditions, such as nutrient concentrations, light and temperature. Conceptually, smaller phytoplankton (e.g., nanophytoplankton) have advantages for light and nutrient harvesting by their relatively high surface to volume ratio, which allows a more efficient exploitation at low nutrient concentrations (Chisholm, 1992). On the other hand, certain diatoms tend to dominate under high-nutrient concentrations because their maximum growth rates are greater than those of smaller phytoplankton. In a system dominated by top-down control, phytoplankton biomass and compositions are controlled by the strength of the grazing pressure. Smaller phytoplankton are more susceptible to microzooplankton, which tend to have higher population growth rates relative to the slowly responding larger zooplankton. While diatoms can escape from size-selective microzooplankton grazing, they suffer the grazing by meso- and macrozooplankton. Based on these concepts, we quantitatively investigated the role of each ecophysiological process (physiological rate such as photosynthesis and grazing rates) in determining the community structure in the models.

\section{Methods}

\subsection{Characteristics of the MAREMIP phase 0 PFT models}

This section briefly summarizes the characteristics of four global PFT models: PISCES, NEMURO, PlankTOM5 and CCSM-BEC. A detailed description of the growth and grazing equations is given in the Appendixes A and B, including the relevant parameter values. For the detailed general 
descriptions of each model, we refer to the indicated original publications (PISCES, Aumont et al., 2006; NEMURO, Kishi et al., 2007; PlankTOM5, Buitenhuis et al., 2010; and CCSM-BEC, Moore et al., 2004) and to the other intercomparison papers of MAREMIP phase 0 (Sailley et al., 2013 and Vogt et al., 2013).

PISCES represents two phytoplankton functional types ( $p$ PFTs: silicifying diatoms and nanophytoplankton, the mixed group of small phytoplankton dominating background primary production in many ocean basins, and most tropical areas) and two zooplankton functional types ( $z$ PFTs: micro- and mesozooplankton). Phytoplankton growth is limited by the availability of nutrients $\left(\mathrm{NO}_{3}, \mathrm{NH}_{4}, \mathrm{PO}_{4}, \mathrm{Si}\right.$, $\mathrm{Fe}$ ), light and temperature. For the nutrient limitation of growth, a Michaelis-Menten relationship is used (Michaelis and Menten, 1913). For the light limitation, the steadystate solution of the photoacclimation process of Geider et al. (1998) is represented in this model. For the temperature dependency, a relationship based on the $Q_{10}$ is used. The $\mathrm{C}: \mathrm{N}: \mathrm{P}$ ratios for all PFTs are assumed constant, while the internal ratio of $\mathrm{Fe}: \mathrm{C}, \mathrm{Chl}: \mathrm{C}$ and $\mathrm{Si}: \mathrm{C}$ of phytoplankton are predicted by the model. PISCES is coupled to an ocean general circulation model (OGCM), NEMO version 3.2 (Madec, 2008) with a horizontal resolution of $2^{\circ} \times 0.5 \sim 2^{\circ}$ and 31 vertical levels.

NEMURO (Kishi et al., 2007) represents two $p$ PFTs (diatoms and nanophytoplankton) and three $z$ PFTs (micro-, meso- and macrozooplankton). Phytoplankton growth is limited by the availability of nutrients $\left(\mathrm{NO}_{3}, \mathrm{NH}_{4}, \mathrm{Si}\right)$, light and temperature. A simplified formulation for the iron limitation of growth is employed in the original NEMURO used during MAREMIP phase 0. For the nutrient limitation and temperature dependency of growth, similar types of relationships as those of PISCES are used, but with different parameter values. For light limitation, the relationship of Steel et al. (1962) is used. One of the characteristics of NEMURO is that mesozooplankton mainly represents a type of copepod, which has ontogenetic vertical migration (e.g., Mackas and Tsuda, 1999). Therefore, in the temperate and high latitude oceans $\left(>30^{\circ} \mathrm{N}\right)$ of the Northern Hemisphere, copepods appear in the surface ocean in April, and migrate into the deep ocean in September. The timing of zooplankton migration is opposite in the Southern Hemisphere $\left(>30^{\circ} \mathrm{S}\right)$. The $\mathrm{C}: \mathrm{N}: \mathrm{Si}$ ratios and $\mathrm{Chl}: \mathrm{C}$ ratio for all PFTs are assumed constant in the model. The variables for the simulation of the carbon cycle are introduced into the original NEMURO in Yamanaka et al. (2004). NEMURO is coupled to an OGCM, COCO (CCSR Ocean Component Model; Hasumi, 2006) version 3.4, which has a horizontal resolution of $1^{\circ} \times 1^{\circ}$ and 54 vertical levels (Aita et al., 2003, 2007).

PlankTOM5 represents three $p$ PFTs (diatoms, nanophytoplankton and coccolithophores as calcifiers) and two $z$ PFTs (micro- and mesozooplankton). Phytoplankton growth is limited by the availability of nutrients $\left(\mathrm{PO}_{4}, \mathrm{Si}, \mathrm{Fe}\right)$, light and temperature with relationships similar to those used in the other models, but using a different parameter set (Buitenhuis et al., 2010). The $\mathrm{C}: \mathrm{P}$ ratios of all PFTs are fixed, while the internal ratios of $\mathrm{Fe}: \mathrm{C}, \mathrm{Chl}: \mathrm{C}$ and $\mathrm{Si}: \mathrm{C}$ of phytoplankton are predicted by the model. PlankTOM5 is coupled to the NEMO OGCM version 2.3, with a horizontal resolution of $2^{\circ} \times 0.5 \sim 2^{\circ}$ and 31 vertical levels.

CCSM-BEC represents three pPTFs (diatoms, nanophytoplankton and diazotrophs as nitrogen fixers) and one generic $z$ PFT (Moore et al., 2004). As in PISCES, phytoplankton growth is limited by the availability of nutrients $\left(\mathrm{NO}_{3}, \mathrm{NH}_{4}\right.$, $\mathrm{PO}_{4}, \mathrm{Si}, \mathrm{Fe}$ ), light and temperature. The relationships of all limitation factors for growth are similar to those of PISCES and PlankTOM5, although the parameter values are different. CCSM-BEC is coupled to the CCSM physical model with a horizontal resolution of $3.6^{\circ} \times 0.8 \sim 1.8^{\circ}$ and 25 vertical levels.

A hindcast experiment was conducted by all groups. As each PFT model is coupled to a different physical model, for the initial conditions and biogeochemical spin-up, we refer to the indicated original publications describing each model, respectively (PISCES, Aumont et al., 2006; NEMURO, Aita et al., 2007; PlankTOM5, Buitenhuis et al., 2010; and CCSMBEC, Moore et al., 2004). All models are driven by a common forcing, the NCEP/NCAR data. Surface monthly averaged model output for the period of 1996-2007 was stored for plankton biomass, nutrients and chlorophyll $a$ (Chl $a$ ) concentrations and important physical and environmental variables (i.e., temperature, salinity, and mixed layer depth). Data were regridded onto a $1^{\circ} \times 1^{\circ}$ horizontal grid.

\subsection{Estimated PFTs distribution from satellite observations}

For the model evaluation, we used phytoplankton composition data estimated from satellite observations using two different algorithms (Hirata et al., 2011; Alvain et al., 2005, 2008). Hirata et al. (2011) presented synoptic-scale relationships between $\mathrm{Chl} a$ concentration and phytoplankton pigment groups (i.e., seven PFTs including diatoms, dinoflagellates, green algae, haptophytes, picoeukaryotes, prokaryotes and Prochlorococcus) using phytoplankton pigment data derived from high performance liquid chromatography (HPLC) in the world's ocean (Fig. 1). For diatoms, they proposed one global relationship as follows:

$$
\begin{aligned}
(\% \text { of Diatoms })= & {[1.3272+} \\
& \left.\exp \left(-3.9828 \times \log _{10}[\mathrm{Chl}]+0.1953\right)\right]^{-1} \times 100 .(1)
\end{aligned}
$$

The root mean square errors (RMSE) of this estimation for diatoms was $6.3 \%$ over the entire $\mathrm{Chl} a$ range observed in situ $\left(0.02<\mathrm{Chl} a<4.26 \mathrm{mg} \mathrm{Chl} \mathrm{m}^{-3}\right)$. Based on this relationship with SeaWiFS satellite $\mathrm{Chl} a$, they estimated the monthly surface distribution of the diatom fraction. Alvain et al. (2008) estimated the frequency of dominance as the relative time in a month that a certain PFT constitutes the majority of biomass for the following 5 PFTs: 


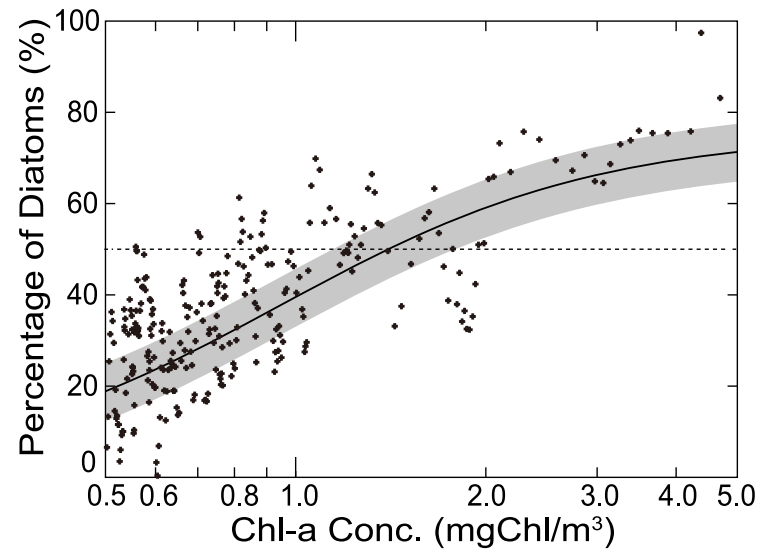

Fig. 1. Black dots show the percentage of diatoms with respect to total Chl $a$ concentration derived from HPLC pigment data in the world's ocean (Hirata et al., 2011). Solid line shows one global relationship between $\mathrm{Chl} a$ concentration and fraction of diatoms estimated from the HPLC data (Eq. 1). The grey-shaded area is the RMSE of this estimation. Note that the $x$ axis uses a log scale.

diatoms, nanoeucaryotes, Prochlorococcus, Synechococcus and Phaeocystis-like taxa, using the PHYSAT algorithms to detect the major dominant phytoplankton groups from anomalies of the water-leaving radiation measured by ocean color satellites. The PHYSAT method was evaluated using in situ measurements (Alvain et al., 2012), and the evaluation showed $73 \%$ correct identification of dominance for diatoms and $82 \%$ correct identification of dominance for nanoflagellates. We converted the monthly mean frequency of diatom dominance of Alvain et al. (2008) to the monthly averaged percentage of diatoms for comparison with model results. This simplified estimation might underestimate the percentage of diatoms in case of steep diatom blooms that have time scales shorter than one month. This is because even if the monthly mean frequency of diatom dominance is low, the contributions of diatoms to the monthly average of the total phytoplankton biomass could be high.

\subsection{Definition of the relative growth ratio}

In order to understand the effect of bottom-up control on phytoplankton competition during blooms, we compared the differences in the growth rate between diatoms and nanophytoplankton as a proxy for bottom-up control. The growth rate of the current PFT models in MAREMIP phase 0 can be described with the common formula:

$$
\begin{aligned}
(\text { Growth rate })_{\mathrm{P}_{i}}= & V_{\max }^{\mathrm{P}_{i}} \times f\left(N_{\lim }\right)_{\mathrm{P}_{i}} \times f\left(L_{\text {lim }}\right)_{\mathrm{P}_{i}} \\
& \times f\left(T_{\mathrm{dep}}\right)_{\mathrm{P}_{i}} \times\left[\mathrm{P}_{i}\right],
\end{aligned}
$$

where $V_{\max }^{\mathrm{P}_{i}}$ is the maximum growth rate, a constant for each phytoplankton type $\mathrm{P}_{i}$. In this equation, the maximum growth rate is limited by the nutrient and light limitation terms (i.e., $f\left(N_{\mathrm{lim}}\right)_{\mathrm{P}_{i}}$ and $\left.f\left(L_{\mathrm{lim}}\right)_{\mathrm{P}_{i}}\right)$ and modified by the temperature dependency of growth (i.e., $\left.f\left(T_{\mathrm{dep}}\right)_{\mathrm{P}_{i}}\right)$. In addition, the growth rate depends on the concentration of each phytoplankton functional type $\left[\mathrm{P}_{i}\right]$. To understand how environmental conditions affect the differences in growth rate, we use the specific growth rate in $\mathrm{d}^{-1}$, which is the growth rate normalized by the concentration of each $p$ PFT.

$$
\begin{aligned}
\text { (Specific growth rate })_{\mathrm{P}_{i}} & =(\text { Growth rate })_{\mathrm{P}_{i}} /\left[\mathrm{P}_{i}\right] \\
& =V_{\max }^{\mathrm{P}_{i}} \times f\left(N_{\lim }\right)_{\mathrm{P}_{i}} \\
& \times f\left(L_{\lim }\right)_{\mathrm{P}_{i}} \times f\left(T_{\mathrm{dep}}\right)_{\mathrm{P}_{i}} .
\end{aligned}
$$

To quantify the effect of bottom-up control on phytoplankton competition, we define a "relative growth ratio" as follows:

$$
\begin{aligned}
& (\text { Relative growth ratio })=\log _{10}\left(\frac{(\text { Specificgrowthrate })_{\mathrm{P}_{\mathrm{D}}}}{(\text { Specificgrowthrate })_{\mathrm{P}_{\mathrm{N}}}}\right) \\
& \left.=\log _{10} \text { (Specific growth rate }\right)_{\mathrm{P}_{\mathrm{D}}} \\
& \left.-\log _{10} \text { (Specific growth rate }\right)_{\mathrm{P}_{\mathrm{N}}} \text {. }
\end{aligned}
$$

In this equation, $\mathrm{D}$ represents diatoms, and $\mathrm{N}$ nanophytoplankton. As we use the logarithms of the relative growth ratio, the relative growth ratio becomes positive when the specific growth rate of diatoms exceeds that of nanophytoplankton. Conversely, negative values indicate an advantage of nanophytoplankton in growth. We estimated the relative growth ratio using monthly averaged data of nutrients, light intensity, temperature and phytoplankton concentration for each model.

In order to identify the contribution of each term to the relative growth ratio separately, we decompose the logarithm of the relative growth ratio as follows:

$$
\begin{aligned}
(\text { Relative growth ratio })= & \log _{10}\left(\frac{V_{\max }^{\mathrm{P}_{\mathrm{D}}}}{V_{\max }^{\mathrm{P}_{\mathrm{N}}}}\right) \\
& +\log _{10}\left(\frac{f\left(N_{\lim }\right)_{\mathrm{P}_{\mathrm{D}}}}{f\left(N_{\lim }\right)_{\mathrm{P}_{\mathrm{N}}}}\right) \\
& +\log _{10}\left(\frac{f\left(L_{\lim }\right)_{\mathrm{P}_{\mathrm{D}}}}{f\left(L_{\mathrm{lim}}\right)_{\mathrm{P}_{\mathrm{N}}}}\right) \\
& +\log _{10}\left(\frac{f\left(T_{\mathrm{dep}}\right)_{\mathrm{P}_{\mathrm{D}}}}{f\left(T_{\mathrm{dep}}\right)_{\mathrm{P}_{\mathrm{N}}}}\right) .
\end{aligned}
$$

In this equation, the change in the relative growth ratio is determined as the sum of the individual (competition) terms. To represent the differences in physiology between diatoms and nanophytoplankton, each model used different limitation (or dependency) terms with taxon-specific parameters (Appendix A). In PISCES, diatoms have the same maximum growth rate as nanophytoplankton. The difference in growth rate can only be caused by the differences in the nutrient and light dependencies. In NEMURO, the maximum growth rate and nutrient dependency terms are different for diatoms and nanophytoplankton. In PlankTOM5, the maximum growth rate, nutrient and light dependencies are different for all PFTs. In CCSM-BEC, the differences in PFTs 
are caused by the nutrient and light limitation terms. A common temperature dependency based on Eppley (1972) is employed in all models, with the same parameters for diatoms and nanophytoplankton. Thus, the temperature dependency of the growth rate does not affect the phytoplankton competition in the current PFT models in MAREMIP phase 0 , and it can be neglected in the subsequent analysis.

In an optimal environment without any nutrient and light limitations, diatoms have larger specific growth rates in NEMURO and PlankTOM5, due to the differences in the maximum growth rate, i.e., the relative growth ratios become 0.3 in NEMURO and 0.18 in PlankTOM5 (Appendix A, Table A1); diatoms would thus dominate barring differences in loss terms (e.g., mortality, aggregation, sinking, and grazing).

\subsection{Definition of the relative grazing ratio}

In order to understand the effects of top-down control on phytoplankton competition, we compared the differences in grazing rate for diatoms and nanophytoplankton. The grazing rate on phytoplankton in the current PFT models in MAREMIP phase 0 can be described by the following generic formula:

$$
\begin{aligned}
(\text { Grazing rate })_{\mathrm{P}_{i}}^{\mathrm{Z}_{i}}= & G_{\max }^{\mathrm{Z}_{i}} \times f\left(T_{\text {dep }}\right)_{\mathrm{Z}_{i}} \\
& \times f(\text { Food availability })_{\mathrm{P}_{i}}^{\mathrm{Z}_{i}} \times\left[\mathrm{Z}_{i}\right] .
\end{aligned}
$$

The maximum grazing rate $G_{\max }^{Z_{i}}$ is modified by a temperature dependency term $f\left(T_{\mathrm{dep}}\right)_{\mathrm{Z}}$ and a food availability term containing the grazing preferences of zooplankton $f$ (Food availability) ${ }_{\mathrm{P}_{i}}$. Here the food availability term also includes the saturation relationships of a Holling type II in PISCES and PlankTOM5 (Eq. B5), a Holling type III in CCSM-BEC (Eqs. B14, B15) or an Ivlev equation in NEMURO (Eqs. B11, B12). In addition, the grazing rate depends on the concentration of each zooplankton $\left[\mathrm{Z}_{i}\right]$. In analogy to the specific growth rate for the bottom-up control, we defined the specific grazing rate in $\mathrm{d}^{-1}$, which is the grazing rate normalized by phytoplankton concentration.

(Specific grazing rate $)_{\mathrm{P}_{i}}^{\mathrm{Z}_{i}}=\left(\frac{(\text { Grazing rate })_{\mathrm{P}_{i}}^{\mathrm{Z}_{i}}}{\left[\mathrm{P}_{i}\right]}\right)$.

Based on this specific grazing rate, we defined a "relative grazing ratio" for each zooplankton type as an indicator of top-down control as follows:

$$
\begin{aligned}
{\text { (Relative grazing ratio })^{Z_{i}}}^{Z} & \log _{10}\left(\frac{(\text { Specific grazing rate })_{\mathrm{P}_{\mathrm{N}}}^{Z_{i}}}{(\text { Specific grazing rate }))_{\mathrm{P}_{\mathrm{D}}}^{Z_{i}}}\right) \\
& =\log _{10}(\text { Specific grazing rate })_{\mathrm{P}_{\mathrm{N}}} \\
& -\log _{10}(\text { Specific grazing rate }){ }_{\mathrm{P}_{\mathrm{D}}}^{Z_{i}} .
\end{aligned}
$$

The relative grazing ratio is mainly determined by the differences in the maximum grazing rate, in grazing preferences and in the relative abundance of diatoms and nanophytoplankton. The full equations for the relative grazing ratio are given in the Appendix B. Like for the relative growth ratio, a positive relative grazing ratio leads to an increase in the percentage of diatoms.

\subsection{Offline estimation of biological rates and definition of blooming region}

We calculated biological rates such as the relative growth and the grazing rates offline using the set of model equations and the data of the biogeochemical and physical output fields of MAREMIP phase 0 models. The offline estimations of biological rates based on monthly averaged fields are fully able to capture the monthly averaged features of seasonal variation of the lower trophic level ecosystem including blooms. However, as the timescales of blooms are generally shorter than one month, for further precise analysis it is desirable to resolve the different mechanisms of initiation and termination of blooms by online simulation or using temporally high resolution data.

In this study, we focused on the mechanism of phytoplankton competition at the timing of bloom maximum. For later analysis, we defined blooming regions as those with surface Chl $a$ concentrations over $0.5 \mathrm{mg} \mathrm{Chl} \mathrm{m}^{-3}$ at the peak timing of the bloom in three selected regions: the North Pacific $\left(115^{\circ} \mathrm{E}-120^{\circ} \mathrm{W}, 20-70^{\circ} \mathrm{N}\right)$, the North Atlantic $\left(80^{\circ} \mathrm{W}-20^{\circ} \mathrm{E}, 20-80^{\circ} \mathrm{N}\right)$, and the Southern Ocean (40$90^{\circ} \mathrm{S}$ ). To understand the regional differences, we also took regional averages of biological rates and plankton biomass in each blooming region in order to examine relationship with bloom magnitude.

\section{Results and discussions}

\subsection{Bloom magnitude and peak timing}

All models reasonably reproduced the observed spatial patterns of maximum Chl $a$ concentration during blooms (Fig. 2a) with high concentrations in the coastal regions and low concentrations in the open oceans. However, in the observations, Chl $a$ concentrations in the coastal regions are much higher than those of the open oceans (e.g., models simulate a maximum of around 3 to $4 \mathrm{mg} \mathrm{Chl} \mathrm{m}^{-3}$ in the coastal regions, but observations are over $10 \mathrm{mg} \mathrm{Chl} \mathrm{m}^{-3}$ locally), and the gradient between onshore and open ocean Chl $a$ is large in the observation. Models do not capture the observed patchiness of blooms. In the North Pacific observations, the main blooming area is situated in the western region. This regional maximum is also captured by all models. In the Southern Ocean, the simulated blooming areas extend widely into lower latitude regions (around $40^{\circ} \mathrm{S}$ ), compared to the observed blooming areas. In particular, NEMURO overestimates the magnitude of blooms in the Southern Ocean. 
(a) Maximum Chl-a Conc.

(b) Timing of Chl-a Maximur

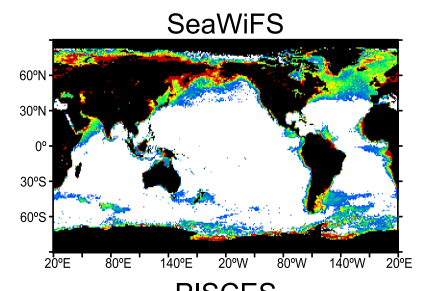

PISCES
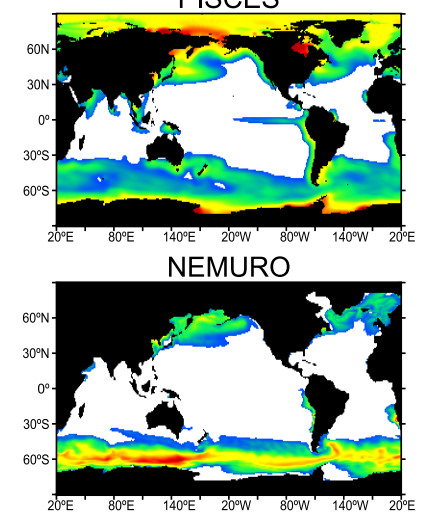

PlankTOM5

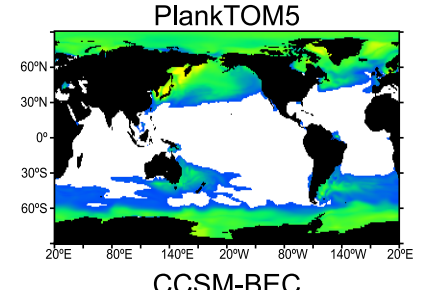

CCSM-BEC
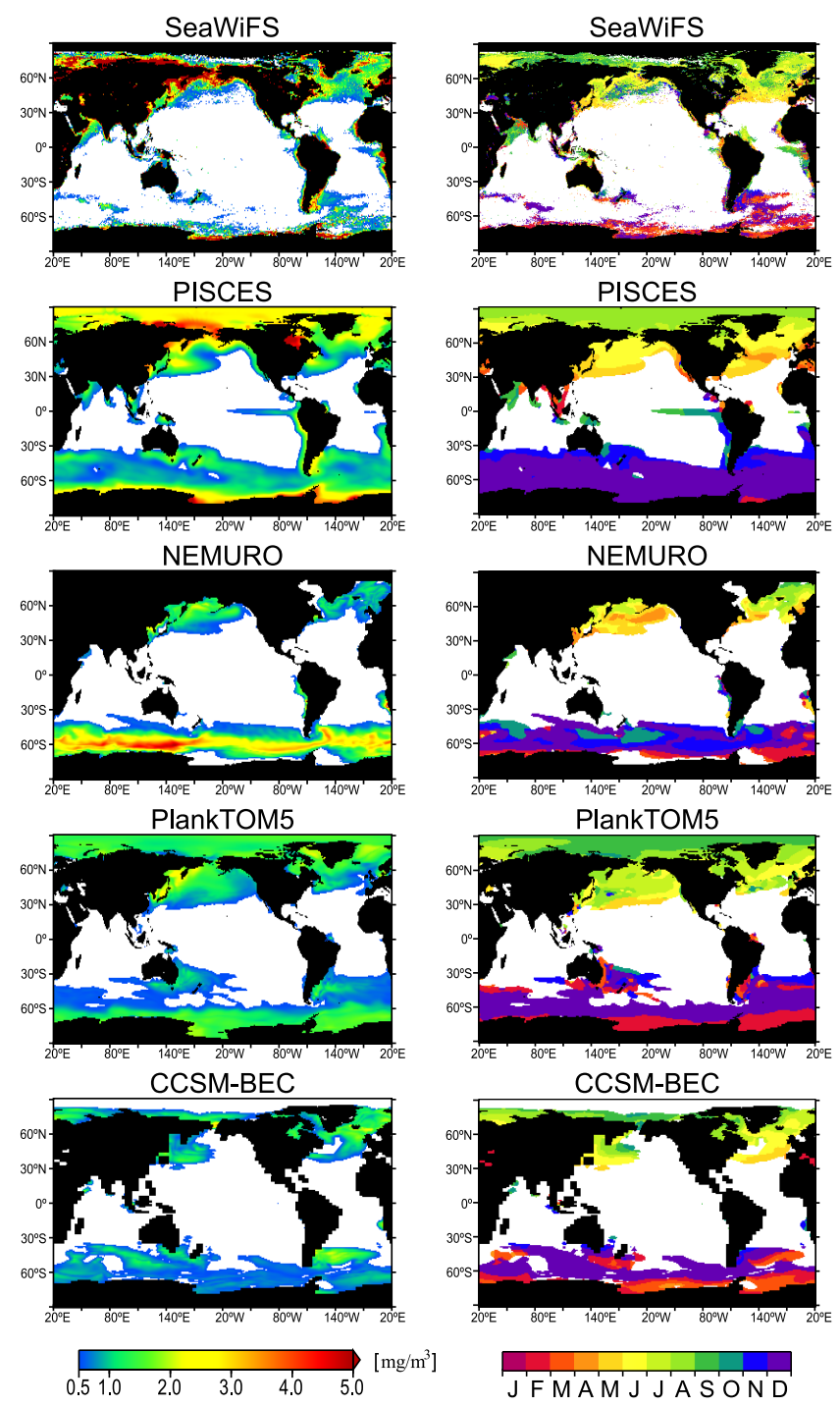

PISCES
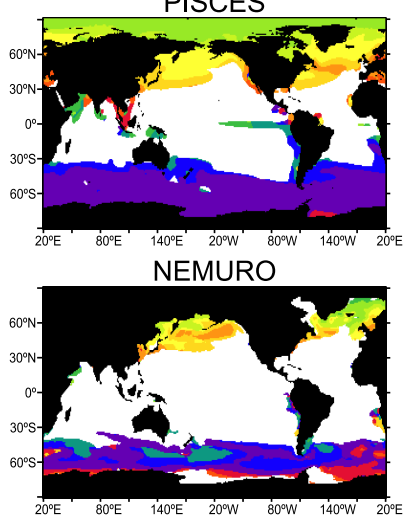

PlankTOM5

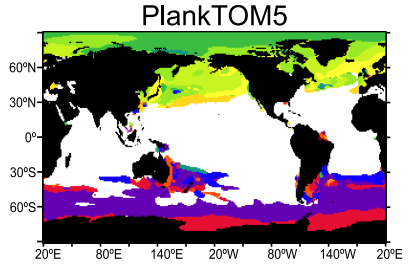

CCSM-BEC

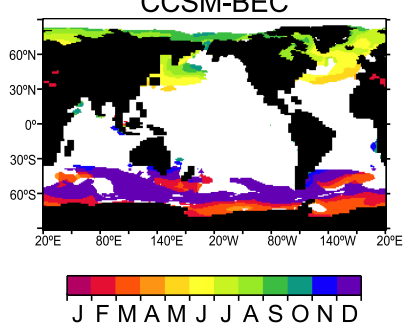

Fig. 2. (a) Distribution of the annual maximum of surface Chl $a$ concentration (i.e., magnitude of blooms). (b) Distributions of the timing of the annual maximum of the surface $\mathrm{Chl} a$ (i.e., peak timing of the bloom). Regions with less than $0.5 \mathrm{mg} \mathrm{Chl} \mathrm{m}^{-3}$ at the timing of the bloom maximum are masked with gray and white colors, respectively.

For SeaWiFS Chl $a$, blooms reach their maximum concentration in April in the low latitude oceans, and in July and August in the high latitude oceans of the Northern Hemisphere (Fig. 2b). In the open ocean of the North Pacific, blooms reach their maximum in September and October. This region corresponds to a high nutrient low $\mathrm{Chl}$ (HNLC; Martin et al., 1994) region. In the Southern Ocean, the blooms reach their maximum in December and January. The model results reasonably reproduced the seasonal shifts of blooming areas from low latitude to high latitude oceans in the Northern Hemisphere. In the HNLC region in the North
Pacific, CCSM-BEC and PlankTOM5 captured well the timing of the bloom maximum in fall. In the Southern Ocean, all models showed peak biomass timing in December and January as observed, except the regions of October and November in NEMURO.

\subsection{Percentage of diatoms at the bloom maximum}

To understand the contribution of diatom's chlorophyll to blooms, we compared the simulated relative percentage of diatoms to the total phytoplankton $\mathrm{Chl} a$ concentration at the peak of the bloom with the satellite estimates of Hirata et al. (2011) and Alvain et al. (2008). Hirata et al. (2011) shows a high fraction of diatoms of over $70 \%$ in the coastal regions in the high latitude oceans (Fig. 3e). In addition, the percentage of diatoms in the North Pacific is much higher than that in the North Atlantic. These regional differences of the percentage of diatoms mainly correspond to the changes in Chl $a$ concentration, since the formulation of Hirata et al. (2011) is a function of the total Chl $a$ concentration (Eq. 1). The percentage of diatoms deduced from the dominance frequency data in Alvain et al. (2008), however, indicates a lower percentage of diatoms of less than $20 \%$ in the North Pacific and the North Atlantic during the maximum of the bloom. In the Southern Ocean, the estimated diatom percentage from Alvain et al. (2008) reached up to $80 \%$ during the month of maximum Chl $a$ (Fig. 3f).

In PISCES, NEMURO and CCSM-BEC, regions with over $70 \%$ diatoms extend widely over all blooming regions. In PISCES (Fig. 3a) the relative abundance of diatoms is high along the coastal regions and low in the open oceans. There are no significant differences between the North Pacific, the North Atlantic and the Southern Ocean. The percentage of diatoms in NEMURO (Fig. 3b), in contrast, shows higher values in the North Pacific than in the North Atlantic, and the percentage of diatoms in the Southern Ocean exceeds $90 \%$. In CCSM-BEC (Fig. 3d), the percentage of diatoms is higher in the open oceans in the North Pacific and in the North Atlantic. In the Southern Ocean, the fraction of diatoms exceeds $90 \%$ along the coastal regions. In PlankTOM5, the percentage of diatoms is lower than that of the other models (Fig. 3c). In parts of the Southern Ocean and the northern part of the North Atlantic, diatoms dominate with a percentage of 60 to $80 \%$. In the North Pacific, diatoms dominated only in a small part of the blooming regions.

The absolute values of the percentage of diatoms in PISCES, NEMURO and CCSM-BEC are close to the results of Hirata et al. (2011). The regional contrast between the North Pacific and the North Atlantic in NEMURO is consistent with the estimation of Hirata et al. (2011). On the other hand, the simulated percentage of diatoms in PlankTOM5 is close to the estimation from Alvain et al. (2008). The wide differences between the satellite estimates preclude a quantitative assessment of the skill of the model. 
(a) PISCES

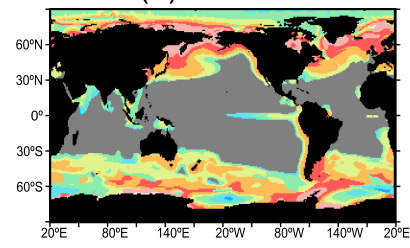

(c) PlankTOM5

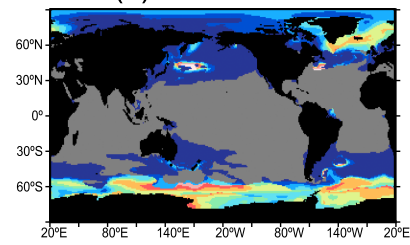

(e) Hirata et al., 2011

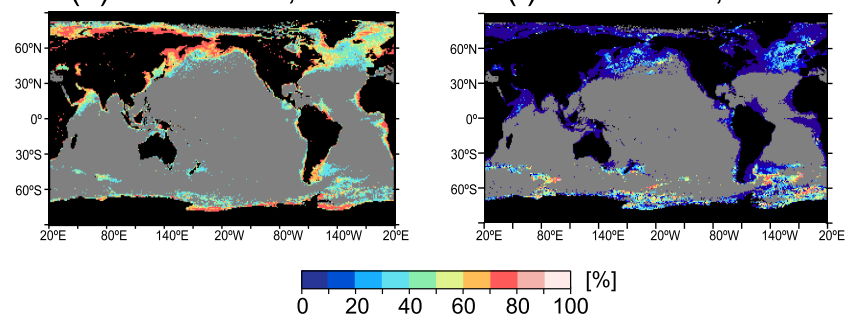

Fig. 3. Distribution of the relative percentage of diatoms with respect to the total phytoplankton concentration at the peak timing of the bloom in Fig. 2b: (a) PISCES, (b) NEMURO, (c) PlankTOM5, (d) CCSM-BEC, and the estimations from satellite observation, (e) Hirata et al. (2011) and (f) Alvain et al. (2008). Regions with less than $0.5 \mathrm{mg} \mathrm{Chl} \mathrm{m}^{-3}$ at the timing of the bloom maximum are masked with gray.

\subsection{Relationship between percentage of diatoms and magnitude of blooms}

We investigated the relationships between the magnitude of blooms and the relative percentage of diatoms in three blooming regions. In the global HPLC pigment data of Hirata et al. (2011), the percentage of diatoms increases from $20 \%$ at $0.5 \mathrm{mg} \mathrm{Chl} \mathrm{m}^{-3}$ to $70 \%$ at $3.0 \mathrm{mg} \mathrm{Chl} \mathrm{m}^{-3}$ (Fig. 1). In the range of lower Chl $a$ concentration, PlankTOM5 has a similar percentage of diatoms as Hirata et al. (2011), around $20 \%$ (Fig. 4c). On the other hand, in the range of higher Chl $a$ concentrations, the results in PISCES, NEMURO and CCSMBEC are close to the result in Hirata et al. (2011) with simulated diatom percentages around 60 to $80 \%$ (Fig. 4a, b, d).

A common feature in all models is that the percentage of diatoms increases over the entire $\mathrm{Chl} a$ range of the blooms. The increasing trend in PISCES and NEMURO is particularly clear with small spatial standard deviations. In PlankTOM5 and CCSM-BEC, there is also an increasing trend of the percentage of diatoms with increase in the magnitude of blooms, but the trend is less clear than that of PISCES and NEMURO, because of large spatial standard deviations. In PlankTOM5, the regional differences are large compared (a) PISCES

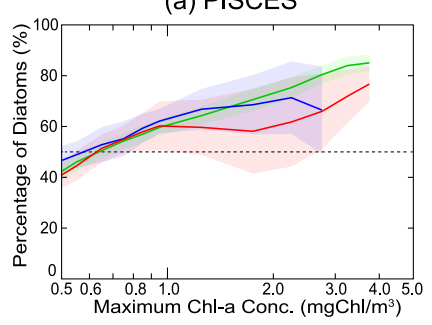

(c) PlankTOM5

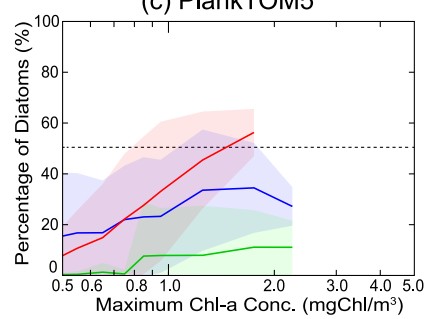

(b) NEMURO

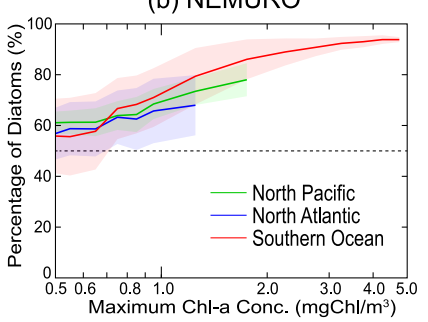

(d) CCSM-BEC

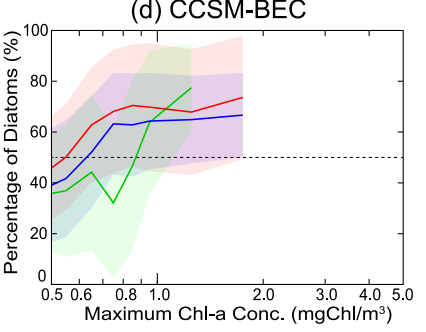

Fig. 4. Percentage of diatoms with respect to total phytoplankton at the peak timing of the bloom as a function of the bloom magnitude (i.e., the annual maximum of $\mathrm{Chl} a$ concentration in the bloom regions): (a) PISCES, (b) NEMURO, (c) PlankTOM5 and (d) CCSMBEC. The colored solid lines are the spatially averaged values in the blooming region (green: the North Pacific, blue: the North Atlantic and red: the Southern Ocean). The color shades are the spatial standard deviation in the blooming region of each model.

to the results of the other models with much higher diatom fractions in the Southern Ocean versus the North Pacific. In CCSM-BEC, for Chl $a$ concentrations $>0.9 \mathrm{mg} \mathrm{Chl} \mathrm{m}^{-3}$, the percentage of diatoms saturates around $60 \%$, and the percentage of diatoms in the North Pacific is lower than in the other regions, like in PlankTOM5.

\subsection{Effect of bottom-up control on the phytoplankton competition}

\subsubsection{Comparison of the relative growth ratio}

In order to understand the effect of bottom-up control on phytoplankton competition during blooms, we compare the relative growth ratio (Eq. 4) in each of the blooming regions among models at the time of the bloom maximum (Fig. 5). In PISCES, the specific growth rate of nanophytoplankton exceeds the rate of diatoms in all blooming regions (i.e., the relative growth ratio is negative over the entire range of the magnitude of blooms in Fig. 5a). Therefore, the high percentage of diatoms in many bloom regions with values over $50 \%$ (Fig. 4a), cannot be explained by the difference in the specific growth rate via bottom-up control. The relative growth ratio has significant regional differences, while the relationship in the percentage of diatoms showed a positive correlation with chlorophyll in all blooming regions. Thus, the effect of bottom-up control in PISCES has an effect of varying 
(a) PISCES

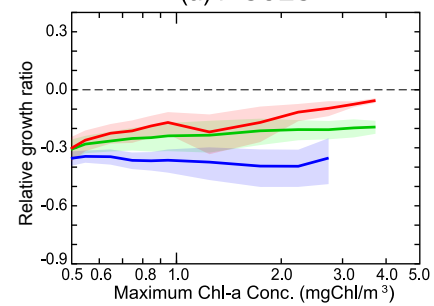

(c) PlankTOM5

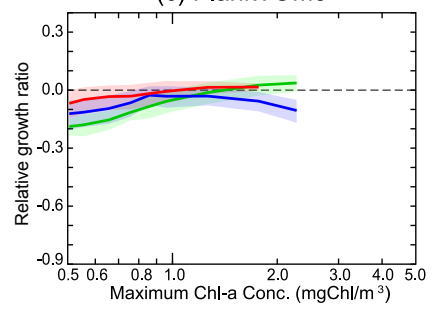

(b) NEMURO

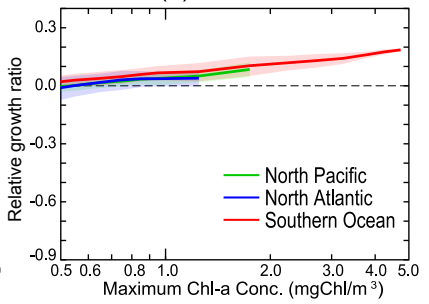

(d) CCSM-BEC

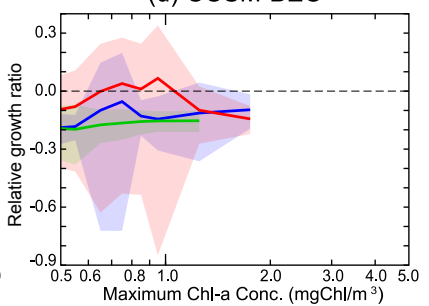

Fig. 5. The relative growth ratio (equivalent to the $\log _{10}$ of the ratio of the diatom to nanophytoplankton specific growth rates, Eq. 5) as a function of the bloom magnitude: (a) PISCES, (b) NEMURO, (c) PlankTOM5 and (d) CCSM-BEC. A positive value means that the diatom specific growth rate exceeds that of nanophytoplankton. The colored solid lines are the spatial averages in blooming regions (green: the North Pacific, blue: the North Atlantic and red: the Southern Ocean). The color shades are the spatial standard deviation of the relative growth ratio in the blooming area of each model. Note that the $x$ axis uses a log scale.

strength on the relative abundance of diatoms in different blooming regions.

In contrast to PISCES, the specific growth rate of diatoms in NEMURO is larger than that of nanophytoplankton in all blooming regions (i.e., the relative growth ratio is positive; Fig. 5b). In addition, the relative growth ratio clearly increases with the magnitude of the bloom. This relationship is the same for all blooming regions, with small spatial standard deviations in the relative growth ratio. Therefore, the increase in the percentage of diatoms with increasing Chl $a$ (Fig. 4b) is reasonably explained by the effect of bottom-up control in NEMURO.

In PlankTOM5, the specific growth rate of nanophytoplankton exceeds that of diatoms, except for blooms with a magnitude of over $1.0 \mathrm{mg} \mathrm{Chl} \mathrm{m}^{-3}$ in the North Pacific and over $1.3 \mathrm{mg} \mathrm{Chl} \mathrm{m}^{-3}$ in the Southern Ocean (Fig. 5c). This relationship in the relative growth ratio is generally consistent with the results of the percentage of diatoms, i.e., nanophytoplankton dominates in most parts of the blooming regions (Fig. 4c). However, the regional differences in the percentage of diatoms are much larger than the differences in the relative growth ratio. In particular, in the North Pacific the percentage of diatoms is much lower than in the North Atlantic, although the relative growth ratio in the North Pacific exceeds the ratio in the North Atlantic in the range of large blooms of over $1.2 \mathrm{mg} \mathrm{Chl} \mathrm{m}^{-3}$. The relatively low per-

centage of diatoms in the North Pacific suggests the importance of top-down control in this blooming region in PlankTOM5. The spatial standard deviations of the relative growth ratio are small compared to that of the percentage of diatoms, in contrast to the result in PISCES. Hence, the relative importance of bottom-up and top-down controls for the phytoplankton competition can vary between regions even within the same model.

In CCSM-BEC, the specific growth rate of nanophytoplankton exceeds the rate of diatoms in all blooming regions except for a part of the Southern Ocean that has a chlorophyll concentration of about $1.0 \mathrm{mg} \mathrm{Chl} \mathrm{m}^{-3}$ (Fig. 5d). However, the percentage of diatoms is much higher than expected from the differences in the relative growth ratio, i.e., diatoms dominate in most of the regions of the Southern Ocean and the North Atlantic, and in regions with more than $1.0 \mathrm{mg} \mathrm{Chl} \mathrm{m}^{-3}$ in the North Pacific (Fig. 4d). These results suggest the importance of top-down control for phytoplankton competition. One of the important characteristics in CCSM-BEC is the large spatial standard deviation of the relative growth ratio in the Southern Ocean and the North Atlantic compared to other models. This means that the ambient environmental conditions for phytoplankton growth differ considerably even in areas with the same magnitude of blooms.

\subsubsection{Comparison of the limitation factors of phytoplankton growth}

The current PFT models employ the same types of bioclimatic relationships to describe the ecophysiological process of phytoplankton growth, and the parameters are chosen within the range of the observational data. However, as shown in Sect. 3.4.1, the response of phytoplankton growth to the surrounding environments can be significantly different between models. This is because the relative importance of each limitation or dependency terms in the specific growth rate (i.e., the maximum growth rate, nutrient and light limitations and temperature dependency) differs between models and for different PFTs.

In PISCES, the relative growth ratio is mainly determined by the nutrient limitation in the entire blooming region (Fig. 6). The contributions of bottom-up control to the dominance of diatoms are summarized in the upper part of Table 1. Nanophytoplankton have a small half saturation constant for nutrient uptake, and thus a growth advantage over the entire range of magnitudes of the bloom compared to diatoms. The nutrient limitation in the North Atlantic is stronger than that in the North Pacific and the Southern Ocean, resulting in the regional differences in the relative growth ratio in Fig. 5. The increasing trend of the relative growth ratio with an increasing magnitude of the bloom is determined by the easing trend of nutrient limitation, as light limitation does not play an important role for the phytoplankton competition at the time of the maximum of the bloom. 
Table 1. Summary of the effects of the bottom-up and the top-down controls on the competition between diatoms and nanophytoplankton in each of the models. Up and Down represent the direction of change in the percentage of diatoms associated with each process. Significant processes in each model are shown with *. Several processes are important only in a specific region (NP: the North Pacific, NA: the North Atlantic, SO: the Southern Ocean). Processes that do not affect phytoplankton competition are designated by "-" (i.e., there are no differences in the parameters used for diatom and nanophytoplankton). The contributions of light limitation in PISCES are small although there are differences in parameter values.

\begin{tabular}{llllll}
\hline \multirow{5}{*}{ Bottom-up } & PISCES & NEMURO & PlankTOM5 & CCSM-BEC \\
\hline & $V_{\max }$ & - & UP* & UP* & - \\
& Nutrient Limit. & Down* & Down* & Down* & Down* \\
& Light Limit. & - & - & Down (NA) & UP (NA, SO)* \\
& Temp. Dep. & - & - & - & - \\
\hline \multirow{5}{*}{ Top-down } & Grazing by & Microzoo. & Microzoo. & Microzoo. & \\
& Zooplankton & Mesozoo. & Meso/Macro & Mesozoo. & UP* \\
& & Down & Down & Down (NP)* & \\
\hline
\end{tabular}
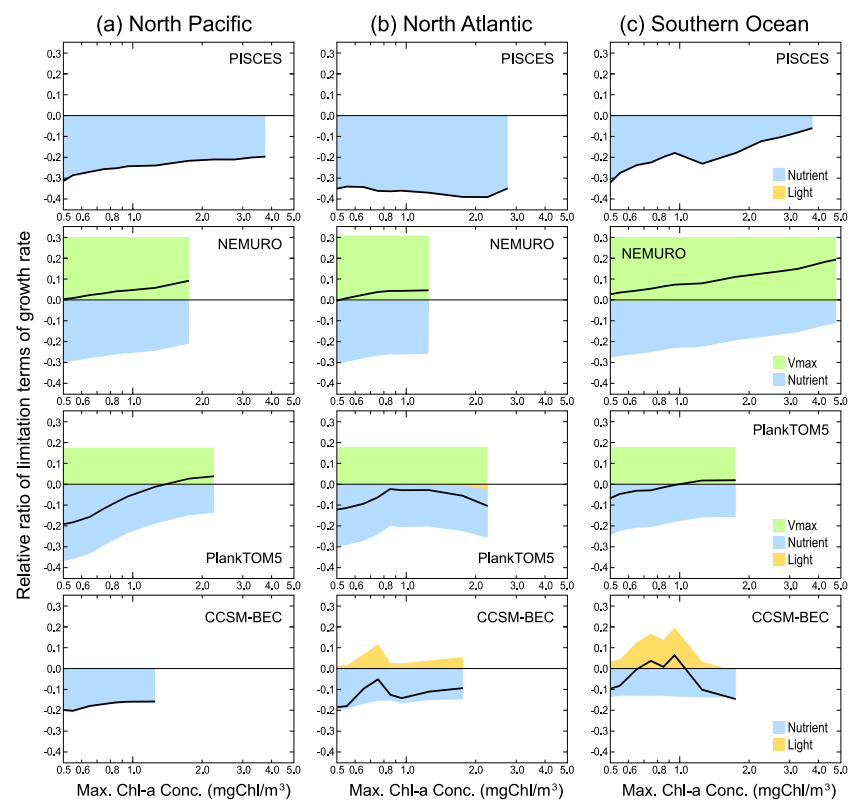

Fig. 6. The relative ratio of limitation or dependency terms (light blue: nutrient, yellow: light and light green: maximum growth rate) of the specific growth rate of diatoms to nanophytoplankton, i.e., each limitation term is divided by the term of nanophytoplankton, as a function of the bloom magnitude: (a) the North Pacific, (b) the North Atlantic and (c) the Southern Ocean. The logarithm scale is used for relative ratios; positive values mean that the limitation terms contribute to the dominance of diatoms, and negative values lead the dominance of nanophytoplankton. The solid black lines show the relative growth ratio (Fig. 5) in each region. The sum of each of the limitation and dependency terms corresponds to the relative growth ratio. Note that the $x$ axis uses a log scale.

In NEMURO, the relative growth ratio is determined by the balance between the difference in the maximum growth rate and the difference in nutrient limitation. The difference in the maximum growth rate contributes to the dominance of diatoms across the entire range of bloom magnitudes. On the other hand, nanophytoplankton has an advantage in the nutrient limitation term due to its smaller half-saturation constant. In NEMURO, there are no significant regional differences in the strength of nutrient limitation between blooming regions. As the maximum growth rate is constant over the entire range of bloom magnitudes, the increasing trend of the relative growth ratio is determined by the relative difference in nutrient limitation between $p$ PFTs.

The relative growth ratio in PlankTOM5 is mainly determined by the balance between differences in the maximum growth rate and nutrient limitation. The increasing trend in the relative growth ratio with the bloom magnitude is also due to the differences in nutrient limitation since the difference in the maximum growth rate is constant. The effect of the nutrient limitation terms on the relative growth ratio is similar in PlankTOM5 and NEMURO. However, since the difference in the maximum growth rate of diatoms and nanophytoplankton is smaller than that of NEMURO, the percentage of diatoms during the bloom maximum is less in PlankTOM5 than in NEMURO (Fig. 4). Light limitation contributes only weakly to the dominance of nanophytoplankton in the range of large blooms in the North Atlantic.

In CCSM-BEC, the difference in nutrient limitation plays an important role for the dominance of nanophytoplankton. The difference in the light limitation plays a significant role for the dominance of diatoms in the wide range of bloom magnitudes in the North Atlantic and the Southern Ocean. The increasing trend of the relative growth ratio through the Chl $a$ range of small blooms (less than $0.8 \mathrm{mg} \mathrm{Chl} \mathrm{m}^{-3}$ ) in the Southern Ocean and the North Atlantic is mainly caused by the light limitation trend since there is no clear increasing trend in the nutrient limitation. 


\subsection{Effect of top-down control on phytoplankton competition}

\subsubsection{Relationship between zooplankton concentration and the magnitude of blooms}

The effect of top-down control on phytoplankton competition is determined by the relative abundance of the different $z$ PFTs, and their characteristic grazing preference for each $p$ PFT. First, we compared the relationship between total zooplankton concentration and the bloom magnitude in different blooming regions as an indicator of the strength of the grazing pressure on phytoplankton (Fig. 7). In PISCES, NEMURO and PlankTOM5, the total zooplankton concentration increases with the magnitude of the bloom, but CCSMBEC shows a constant zooplankton concentration for all bloom magnitudes. The regional differences in averaged zooplankton concentration are not large in all models (less than $1 \mathrm{mg} \mathrm{C} \mathrm{m}^{-3}$ ). But the $z$ PFT concentrations in PISCES and NEMURO are larger than those of PlankTOM5 and CCSMBEC even for the same bloom magnitude. The difference in zooplankton biomass between models, and its variation with bloom magnitude may be due to the differences in ecosystem structure for the higher-trophic levels. For example, whereas PISCES and PlankTOM5 represent two size classes of zooplankton (micro- and mesozooplankton), NEMURO also includes macrozooplankton, and CCSM-BEC represents one generic zooplankton. Furthermore, the implicit treatment of the effect of the top predators such as macrozooplankton or pelagic fish may also account for the observed differences in biomass. These top predators and hence their effect on the lower trophic ecosystem are currently not included in our models. The characteristics of the grazing interactions in the current ecosystem models in MAREMIP phase 0 are discussed in more detail in Sailley et al. (2013).

Each zooplankton type (i.e., micro-, meso-, macro- or generic zooplankton) has different grazing preferences for each phytoplankton type, and the food-web structures also differ between models. We compared the zooplankton composition in blooming regions for each model (Fig. 8).

In PISCES, the zooplankton composition does not depend on the bloom magnitude. Regionally, the contribution of microzooplankton to the total zooplankton concentration is 60 to $70 \%$ in the Southern Ocean, 50 to $60 \%$ in the North Atlantic and 40 to $50 \%$ in the North Pacific. The spatial standard deviation in the percentage of microzooplankton tends to increase for larger blooms. In NEMURO, the percentage of microzooplankton increases with decreasing bloom magnitude (10 to $30 \%$ ). The percentage of meso- and macrozooplankton increases from 30 to $40 \%$ and from 40 to $50 \%$ with increasing bloom magnitude, respectively. The difference in the percentage of microzooplankton between the bloom regions is small with small spatial standard deviation. In the North Pacific, the percentage of macrozooplankton is $20 \%$ higher than in other regions. In PlankTOM5, the percentage (a) PISCES

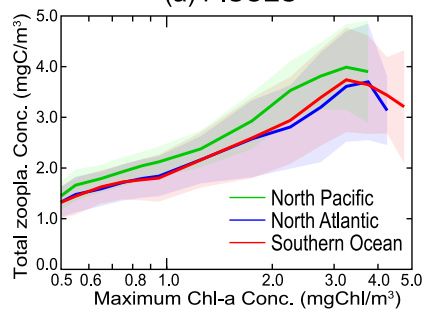

(c) PlankTOM5

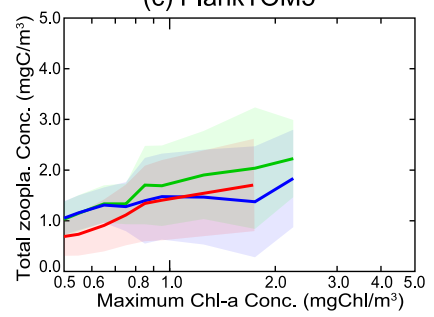

(b) NEMURO

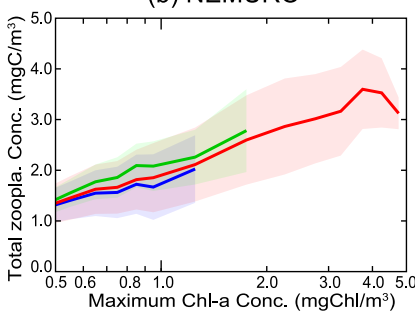

(d) CCSM-BEC

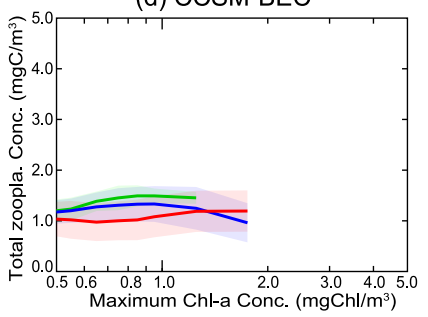

Fig. 7. Relationships between the magnitude of blooms and the total zooplankton concentration at the peak timing of the bloom: (a) PISCES, (b) NEMURO, (c) PlankTOM5 and (d) CCSM-BEC. The colored solid lines are obtained as the spatially averaged values in the blooming region (green: the North Pacific, blue: the North Atlantic and red: the Southern Ocean). The color shades are the spatial standard deviation in the blooming area of each model. Note that the $x$ axis uses a $\log$ scale.

of microzooplankton tends to increase with the bloom magnitude. Although the spatial standard deviations are much larger than in the other models, there are significant regional differences in PlankTOM5. Microzooplankton constitutes 50 to $70 \%$ in the Southern Ocean, 30 to $60 \%$ in the North Atlantic and 20 to $30 \%$ in the North Pacific.

\subsubsection{Comparison of the relative grazing ratio}

To understand the effects of the characteristic grazing preferences for each $z$ PFT on the competition between diatoms and nanophytoplankton, we compared the relative grazing ratio (Eq. 9) in each blooming region at the peak of the bloom between models (Fig. 9). The contributions of top-down control to the dominance of diatoms are summarized in the lower part of Table 1.

In PISCES, the specific grazing rate of microzooplankton on nanophytoplankton is larger than that on diatoms (i.e., the relative grazing ratio is positive in Fig. 9a), and increases with the bloom magnitude. The grazing pressure on nanophytoplankton increases with the bloom magnitude, but less so for the grazing pressure on diatoms. This is because the larger cells of diatoms escape grazing by microzooplankton in observations, and this process is explicitly parameterized as a maximum concentration of diatoms for grazing in PISCES (see Eq. B8 in Appendix B; Aumont et al., 2006). However, both phytoplankton concentrations increase with the bloom magnitude (Figs. 7a, 8a). In contrast 
(a) PISCES

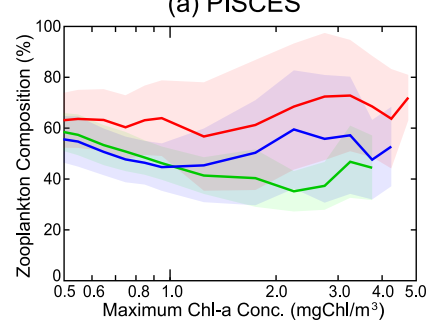

(c) PlankTOM5

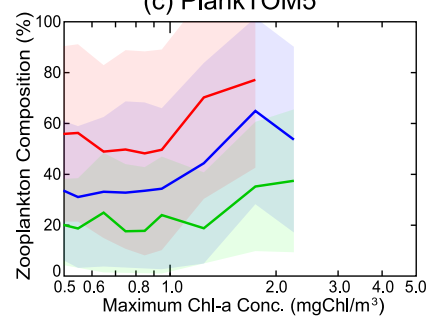

Fig. 8. Relationships between bloom magnitude and the relative abundance of each zooplankton type as a function of maximal Chl $a$ at the bloom maximum: (a) PISCES, (b) NEMURO and (c) PlankTOM5. The colored solid lines represent the percentage of microzooplankton with respect to total zooplankton concentration, obtained from the spatially averaged values in the three blooming regions (green: the North Pacific, blue: the North Atlantic and red: the Southern Ocean). The dotted lines in NEMURO show the percentage of the sum of microzooplankton and macrozooplankton to total zooplankton concentration. Thus the rest of the percentage corresponds to the mesozooplankton in all figures. The color shades are the spatial standard deviation in the blooming area of each model. Note that the $x$ axis uses a $\log$ scale.

to microzooplankton, mesozooplankton prefers diatoms (i.e., the relative grazing ratio is negative in Fig. 9a), and the relative grazing ratio is constant. In PISCES, microzooplankton has a 5.7 times higher maximum grazing rate than mesozooplankton, and the concentration of microzooplankton is similar to that of mesozooplankton during blooms (Fig. 8a). As a result, top-down control by microzooplankton significantly contributes to the dominance of diatoms in PISCES. This is the reason why diatoms widely dominate in most of the bloom areas in PISCES (Fig. 4a), despite their disadvantage in the uptake of nutrient during photosynthesis (Fig. 5a)

In NEMURO, macrozooplankton and microzooplankton graze only on diatoms and nanophytoplankton, respectively. Mesozooplankton graze on both $p$ PFTs. As can be seen in the relative grazing ratio (Fig. 9b), mesozooplankton prefers diatoms to nanophytoplankton, and the preferential grazing pressure on diatoms decreases with the bloom magnitude. This is because the grazing rate of zooplankton saturates at high phytoplankton concentrations in the grazing equation of Ivlev (1955) in NEMURO (Sailley et al., 2013). As a result, the grazing by mesozooplankton on diatoms saturates in the diatom dominated blooms in NEMURO in contrast to the grazing on nanophytoplankton. As the maximum graz- (a) PISCES
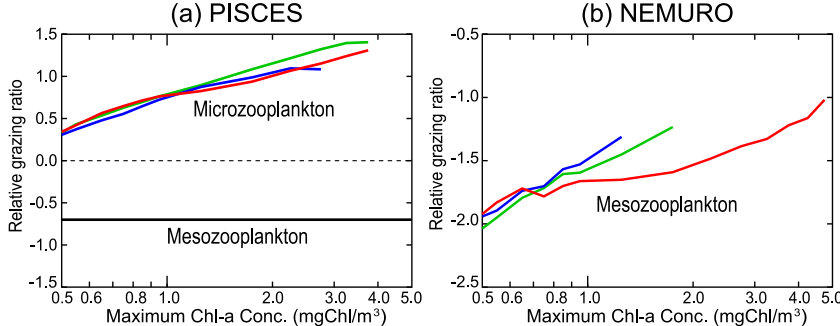

(c) PlankTOM5

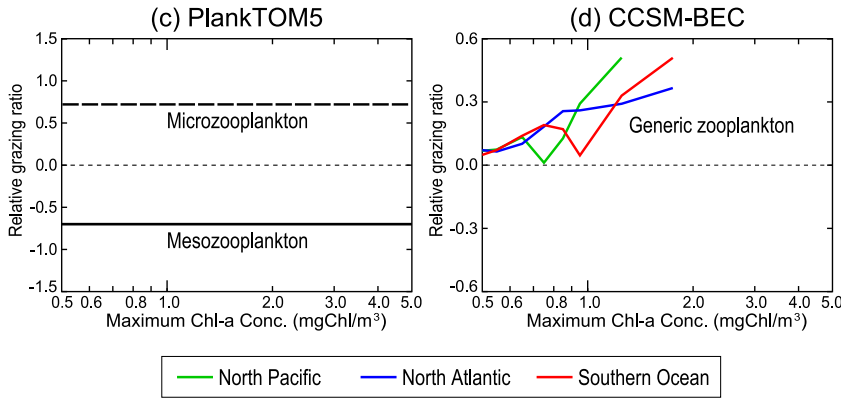

Fig. 9. The relative grazing ratio (equivalent to the specific grazing rate) as a function of the bloom magnitude: (a) PISCES, (b) NEMURO, (c) PlankTOM5 and (d) CCSM-BEC. The colored solid lines represent the ratio of microzooplankton in PISCES, of mesozooplankton in NEMURO and of the generic zooplankton in CCSM-BEC. The lines are obtained as the spatially averaged relative grazing ratio in the bloom regions (green: the North Pacific, blue: the North Atlantic and red: the Southern Ocean). The black solid lines are mesozooplankton, and the black dotted line is microzooplankton in PlankTOM5; these are constant among regions. As the logarithmic scale is used to plot the relative ratio, positive values mean that the grazing terms contribute to the dominance of diatoms, and negative values lead to the dominance of nanophytoplankton. Note that the $x$ axis uses a log scale.

ing rates are almost the same for all zooplankton types in NEMURO, the effect of the top-down control on the competition between phytoplankton types is mainly determined by the characteristics of grazing preferences and the relative abundance of zooplankton (Fig. 8b). Since meso- and macrozooplankton prefer diatoms for grazing, which dominate in all bloom regions ( 70 to $90 \%$ of the total zooplankton concentration), top-down control tends to decrease the percentage of diatoms. However, even in small blooms where the relative growth ratio is close to 0.0 (i.e., there are no differences in the specific growth rate between diatoms and nanophytoplankton) and the relative grazing ratio is at it's most negative value (i.e., the effect of the grazing selection is maximum), the percentage of diatoms is close to $50 \%$. Therefore, the dominance of diatoms during blooms in NEMURO is mainly determined by bottom-up control. This result is consistent with the analysis of Hashioka and Yamanaka (2007b), i.e., the growth phase of blooms is mainly determined by bottomup control, while top-down control has an important role in the termination of blooms. 
PlankTOM5 has the same type of grazing equations as PISCES, although parameter values are different (see Appendix B). In addition, this model does not limit microzooplankton grazing to prey concentrations below a predefined maximum concentration of diatoms (Eqs. B7 and B8 in Appendix B). Microzooplankton and mesozooplankton prefer nanophytoplankton and diatoms, respectively. But the relative grazing ratio for both zooplankton types does not depend on the bloom magnitude (Eqs. B7 and B9 in Appendix B), and hence, there are no regional differences in this ratio. The effect of top-down control on the competition between different phytoplankton is determined by the selective grazing of each zooplankton type, and by the relative abundance between micro- and mesozooplankton. As shown in Fig. 8c, the relative abundance of microzooplankton and mesozooplankton is significantly different between different bloom regions (i.e., mesozooplankton is dominant by $80 \%$ in the North Pacific, while microzooplankton is dominant by 60 to $70 \%$ in the Southern Ocean). As a result, preferential grazing on nanophytoplankton by microzooplankton leads to the increase in the percentage of diatoms in the Southern Ocean. The preferential grazing of diatoms by mesozooplankton, however, contributed to the decrease in the percentage of diatoms in the North Pacific. This result is consistent with the fact that the percentage of diatoms in the North Pacific is much lower than those of the other regions (Fig. 4c), although there are no significant differences in the specific growth rate between bloom regions (Fig. 5c). Therefore, topdown control in PlankTOM5 plays an important role for the regional differences in the phytoplankton competition.

CCSM-BEC represents the differences in the grazing rate on each $p$ PFT using grazing switching by one generic zooplankton, while the other three models represent the grazing selections by different zooplankton types (i.e., microzooplankton prefers nanophytoplankton, and meso- or macrozooplankton prefer diatoms). As CCSM-BEC has only one zooplankton type, the difference in the relative grazing ratio directly represents the effect of top-down control (Fig. 9d). The specific grazing rate of generic zooplankton on nanophytoplankton is larger than that on diatoms (i.e., the relative grazing ratio is positive in Fig. 9d). As a result, top-down control leads to an increase in the percentage of diatoms in all bloom regions. As in PISCES, the relative growth ratio of nanophytoplankton exceeds the one of diatoms in most of the blooming region in CCSM-BEC (Fig. 5d), and the dominance of diatoms is mainly determined by top-down control.

\section{Conclusion}

We investigated the mechanisms governing the competition between diatoms and nanophytoplankton during blooms, using four different PFT models. The model comparison shows that top-down control had an important role for the dominance of diatoms during blooms in PISCES and CCSM-
BEC. On the other hand, bottom-up control was important for the dominance of diatoms in NEMURO and for the dominance of nanophytoplankton in PlankTOM5. These differences in the mechanisms suggest that the response of marine ecosystems to climate change could significantly differ among models.

For further understanding, difference in maximum growth rate between diatoms and nanophytoplankton is one factor that determines whether phytoplankton competition during blooms is controlled by a bottom-up or top-down mechanism. In NEMURO and PlankTOM5, diatoms have greater maximum growth rates than nanophytoplankton. On the other hand, there are no differences in maximum growth rate in PISCES and CCSM-BEC. During the blooming season, when nutrient and light limitation are less important, the difference in the maximum growth rate is potentially the main determinant of PFT dominance. Therefore, efforts are required to determine precisely the difference in the maximum growth rate for these function types based on observations.

In observational studies, maximum growth rates of phytoplankton including diatoms and nanophytoplankton widely vary from 0.2 to $3.3 \mathrm{day}^{-1}$ under conditions of saturating light and nutrient sufficiency (e.g., Williams, 1964; Eppley and Sloan, 1966; Blasco et al., 1982; Schone, 1982; Tang, 1995; Kudo et al., 2000; and Milligan and Harrison, 2000). Several studies have found that maximum growth rate tends to decrease with increasing cell size (Sarthou et al., 2005; Finkel et al., 2010). On the other hand, diatoms tend to have larger maximum growth rate than nanophytoplankton of the same cell size (Tang, 1995; Finkel et al., 2010; Ward et al., 2012) although many diatoms are larger than any nanophytoplankton. The observed maximum growth rate and cell size of each phytoplankton type widely varies, and the ranges of variations overlap. For the evaluation of maximum growth rates in current PFT models it is important to identify the combination of trait values (i.e., parameter values in models) such as cell size and maximum growth rate that are typical of each phytoplankton type for the biogeochemical and ecological functions considered in a given modeling study.

In top-down control, as common features among models, microzooplankton prefers to graze nanophytoplankton, and mesozooplankton prefers diatoms, and microzooplankton has a larger maximum grazing rate than mesozooplankton. These properties are consistent with observational studies for microzooplankton (Buitenhuis et al., 2010); mesozooplankton (Buitenhuis et al., 2006) and macrozooplankton (Moriarty, 2009). Currently, there are large uncertainties in our understanding of the importance of top-down control as a function of the relative concentration of each $z$ PFT type. In PISCES and PlankTOM5, micro- and mesozooplankton concentrations have the same order of magnitude, consistent with observations (Buitenhuis et al., 2006, 2010). In NEMURO, the proportion of microzooplankton is smaller than that of meso- and macrozooplankton. The MARine Ecosystem DATabase (MAREDAT, which aims at the construction 
of a world atlas of biomass of PFTs; ESSD special issue, 2012) will further our understanding of the ocean ecosystem, including the role of top-down control for the competition between phytoplankton. In the case where only one generic zooplankton is modeled, such as in CCSM-BEC, the evaluation of the differences in the maximum grazing rate for each phytoplankton type is important to determine the strength of the top-down control, as the grazing preferences strongly depend on the phytoplankton composition as prey.

This study has been done as a part of MAREMIP phase 0 aiming to understand the current ecosystem (1996-2007) with two other intercomparison studies (Sailley et al., 2013; Vogt et al., 2013). The next phase of MAREMIP (phase 1, which covers model output over the period of 1985-2100) aims to further our understanding of plankton competition, and to project potential impacts on marine ecosystem associated with future climate changes.

\section{Appendix A}

\section{Phytoplankton growth equations and parameters}

The growth rate for each phytoplankton $\left(\mathrm{P}_{i}\right)$ in the current PFT models can be described with the following common formula:

$$
\begin{aligned}
(\text { Growth rate })_{\mathrm{P}_{i}}= & V_{\max }^{\mathrm{P}_{i}} \times f\left(N_{\lim }\right)_{\mathrm{P}_{i}} \times f\left(L_{\text {lim }}\right)_{\mathrm{P}_{i}} \\
& \times f\left(T_{\mathrm{dep}}\right)_{\mathrm{P}_{i}} \times\left[\mathrm{P}_{i}\right] .
\end{aligned}
$$

The maximum growth rate, $V_{\max }^{\mathrm{P}_{i}}$, is limited by nutrient and light limitation terms, $f\left(N_{\lim }\right)_{\mathrm{P}_{i}}$ and $f\left(L_{\lim }\right)_{\mathrm{P}_{i}}$, and modified by the temperature dependency term, $f\left(T_{\mathrm{dep}}\right)_{\mathrm{P}_{i}}$. In addition, the growth rate is dependent on the phytoplankton concentration of each $p$ PFT, $\left[\mathrm{P}_{i}\right]$.

The nutrient limitation term is represented in a similar form for all models, although the limiting nutrients may differ (see Table A1; we only show the parameters that have differences between diatoms and nanophytoplankton, i.e., the maximum growth rate and half saturation constants for nutrient uptake).

$f\left(N_{\lim }\right)_{\mathrm{P}_{i}}=\min \left(V_{\mathrm{P}_{i}}^{\mathrm{NO}_{3} \mathrm{NH}_{4}}, V_{\mathrm{P}_{i}}^{\mathrm{Fe}}, V_{\mathrm{P}_{i}}^{\mathrm{PO}_{4}}, V_{\mathrm{P}_{\mathrm{D}}}^{\mathrm{Si}}\right)$.

$V_{\mathrm{P}_{i}}^{\text {Nutrient }}$ corresponds to the strength of limitation by each nutrient. The limitation by nitrate and ammonium is represented as follows in PISCES and CCSM-BEC:

$$
V_{\mathrm{P}_{i}}^{\mathrm{NO}_{3}, \mathrm{NH}_{4}}=\frac{K_{\mathrm{NH}_{4}}^{\mathrm{P}_{i}}\left[\mathrm{NO}_{3}\right]+K_{\mathrm{NO}_{3}}^{\mathrm{P}_{i}}\left[\mathrm{NH}_{4}\right]}{K_{\mathrm{NO}_{3}}^{\mathrm{P}_{i}} K_{\mathrm{NH}_{4}}^{\mathrm{P}_{i}}+K_{\mathrm{NH}_{4}}^{\mathrm{P}_{i}}\left[\mathrm{NO}_{3}\right]+K_{\mathrm{NO}_{3}}^{\mathrm{P}_{i}}\left[\mathrm{NH}_{4}\right]},
$$

where $K_{\text {Nutrient }}^{\mathrm{P}_{i}}$ is a half saturation constant for nutrient uptake. In NEMURO, the limitation term for nitrogen is represented by a Michaelis-Menten formula with an ammonium inhibition term for nitrate uptake (Wroblewski, 1977) as follows:

$$
\begin{aligned}
V_{\mathrm{P}_{i}}^{\mathrm{NO}_{3} \mathrm{NH}_{4}}= & \frac{\left[\mathrm{NO}_{3}\right]}{K_{\mathrm{NO}_{3}}^{\mathrm{P}_{i}}+\left[\mathrm{NO}_{3}\right]} \exp \left(-\Psi_{\mathrm{P}_{i}}\left[\mathrm{NH}_{4}\right]\right) \\
& +\frac{\left[\mathrm{NH}_{4}\right]}{K_{\mathrm{NH}_{4}}^{\mathrm{P}_{i}}+\left[\mathrm{NH}_{4}\right]} .
\end{aligned}
$$

For other nutrients, the limitations are represented using the Michaelis-Menten formula.

$V_{\mathrm{P}_{i}}^{x}=\frac{[x]}{K_{x}^{\mathrm{P}_{i}}+[x]}$,

where $x$ is $\mathrm{Fe}, \mathrm{PO}_{4}$ or $\mathrm{Si}$. In PISCES, the half saturation constants for iron and silicate depend on phytoplankton concentration and the maximum local yearly concentration of silicate (Pondaven et al., 1998), respectively.

$K_{\mathrm{Fe}}^{\mathrm{P}_{i}}=\frac{K_{\mathrm{Fe}}^{\mathrm{P}_{i} \min } \min \left(\left[\mathrm{P}_{i}\right],\left[\mathrm{P}_{i \max }\right]\right)+K_{\mathrm{Fe}}^{\mathrm{P}_{i} \max } \max \left(0,\left[\mathrm{P}_{i}\right]-\left[\mathrm{P}_{i \max }\right]\right)}{\min \left(\left[\mathrm{P}_{i}\right],\left[\mathrm{P}_{i \max }\right]\right)+\max \left(0,\left[\mathrm{P}_{i}\right]-\left[\mathrm{P}_{i \max }\right]\right)}$,

$K_{\mathrm{Si}}^{\mathrm{D}}=K_{\mathrm{Si}}^{\min }+K_{\mathrm{Si}}^{\max } \frac{\left[\mathrm{Si}_{\max }\right]^{2}}{K_{\mathrm{Si}}^{2}+\left[\mathrm{Si}_{\max }\right]^{2}}$.

For the parameterization of light limitation, PISCES and CCSM-BEC employed the relationship of Geider et al. (1998), and it depends on the growth rate, a Chl/ C ratio in phytoplankton, $\theta_{\mathrm{P}_{i}}$, and the light intensity given as PAR.

$f\left(L_{\lim }\right)_{\mathrm{P}_{i}}=\left(1-\exp \left(\frac{-\alpha \theta \mathrm{P}_{i}[\mathrm{PAR}]}{V_{\max }^{\mathrm{P}_{i}} \times f\left(T_{\mathrm{dep}}\right) \times f\left(N_{\mathrm{lim}}\right)_{\mathrm{P}_{i}}}\right)\right)$.

$\alpha$ is an initial slope of the P-I curve. PlankTOM5 employs the same types of relationship, but it uses a balanced growth solution for the light limitation:

$f\left(L_{\mathrm{lim}}\right)_{\mathrm{P}_{i}}=\left(1-\exp \left(\frac{-\alpha[\mathrm{PAR}]}{V_{\max }^{\mathrm{P}_{i}}}\right)\right)$,

In NEMURO, light limitation is parameterized using the relationship of Steel (1962) as follows:

$f\left(L_{\mathrm{lim}}\right)_{\mathrm{P}_{i}}=\frac{[\mathrm{PAR}]}{I_{\mathrm{opt}}} \exp \left(1-\frac{[\mathrm{PAR}]}{I_{\mathrm{opt}}}\right)$.

$I_{\mathrm{opt}}$ is an optimal light intensity for phytoplankton growth, and the parameter values are the same for diatoms and nanophytoplankton. For the temperature dependency term, the $Q_{10}$ relationship is employed in all the models, and there are no parameter differences between diatoms and nanophytoplankton. We used surface PAR from the NCEP/NCAR data. 
Table A1. Parameter list for the maximum growth rates and half-saturation constants for nutrient uptake.

\begin{tabular}{|c|c|c|c|}
\hline Parameter & Value & Unit & Description \\
\hline \multicolumn{4}{|l|}{ PISCES } \\
\hline 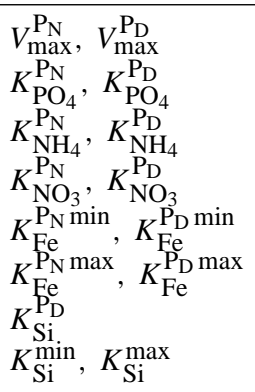 & $\begin{array}{l}0.66,0.66 \\
0.4,0.8 \\
0.0135,0.065 \\
0.26,1.3 \\
0.02,0.1 \\
0.08,0.4 \\
3.0 \\
1.0,7.0\end{array}$ & 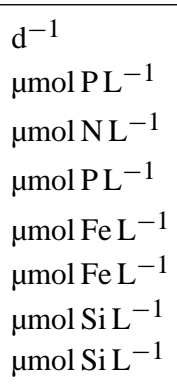 & $\begin{array}{l}\text { Maximum growth rate at } 0^{\circ} \mathrm{C} \\
\text { Half saturation constant for phosphate } \\
\text { Half saturation constant for ammonium } \\
\text { Half saturation constant for nitrate } \\
\text { Half saturation constant for iron (min) } \\
\text { Half saturation constant for iron (max) } \\
\text { Half saturation constant for silicate } \\
\text { Half saturation constant for silicate(min, max) }\end{array}$ \\
\hline \multicolumn{4}{|l|}{ NEMURO } \\
\hline $\begin{array}{l}V_{\max }^{\mathrm{P}_{\mathrm{N}}}, V_{\mathrm{max}}^{\mathrm{P}_{\mathrm{D}}} \\
K_{\mathrm{NH}_{4}}^{\mathrm{P}_{\mathrm{N}}}, K_{\mathrm{NH}}^{\mathrm{P}_{\mathrm{D}}} \\
K_{\mathrm{NO}_{\mathrm{N}}}^{\mathrm{P}_{3}}, K_{\mathrm{NO}_{3}}^{\mathrm{P}_{\mathrm{D}}} \\
K_{\mathrm{Fe}}^{\mathrm{P}_{\mathrm{N}}}, K_{\mathrm{Fe}}^{\mathrm{PD}_{2}} \\
K_{\mathrm{Si}}^{\mathrm{P}_{\mathrm{D}}}\end{array}$ & $\begin{array}{l}0.8,0.4 \\
0.1,0.3 \\
1.0,3.0 \\
0.08,0.2 \\
6.0\end{array}$ & $\begin{array}{l}\mathrm{d}^{-1} \\
\mu \mathrm{mol} \mathrm{N} \mathrm{L} \\
\mu \mathrm{mol} \mathrm{N} \mathrm{L} \\
\mu \mathrm{mol} \mathrm{Fe} \mathrm{L}^{-1} \\
\mu \mathrm{mol} \mathrm{Si} \mathrm{L}\end{array}$ & $\begin{array}{l}\text { Maximum growth rate at } 0^{\circ} \mathrm{C} \\
\text { Half saturation constant for ammonium } \\
\text { Half saturation constant for nitrate } \\
\text { Half saturation constant for iron } \\
\text { Half saturation constant for silicate }\end{array}$ \\
\hline \multicolumn{4}{|l|}{ PlankTOM5 } \\
\hline $\begin{array}{l}V_{\max }^{\mathrm{P}_{\mathrm{N}}}, V_{\max }^{\mathrm{P}_{\mathrm{D}}} \\
K_{\mathrm{PO}_{\mathrm{N}}}^{\mathrm{P}_{\mathrm{N}}}, K_{\mathrm{PO}_{4}}^{\mathrm{P}_{\mathrm{D}}} \\
K_{\mathrm{Fe}}^{\mathrm{P}_{\mathrm{N}}}, K_{\mathrm{Fe}}^{\mathrm{P}_{\mathrm{D}}} \\
K_{\mathrm{Si}}^{\mathrm{P}_{\mathrm{D}}}\end{array}$ & $\begin{array}{l}0.4,0.6 \\
78,417 \\
0.04,0.12 \\
4.0\end{array}$ & $\begin{array}{l}\mathrm{d}^{-1} \\
\mu \mathrm{mol} \mathrm{PL} \mathrm{L}^{-1} \\
\mu \mathrm{mol} \mathrm{Fe} \mathrm{L}^{-1} \\
\mu \mathrm{mol} \mathrm{Si} \mathrm{L}\end{array}$ & $\begin{array}{l}\text { Maximum growth rate at } 0^{\circ} \mathrm{C} \\
\text { Half saturation constant for phosphate } \\
\text { Half saturation constant for iron } \\
\text { Half saturation constant for silicate }\end{array}$ \\
\hline \multicolumn{4}{|l|}{ CCSM-BEC } \\
\hline $\begin{array}{l}V_{\max }^{\mathrm{P}_{\mathrm{N}}}, V_{\max }^{\mathrm{P}_{\mathrm{D}}} \\
K_{\mathrm{PO}_{4}}^{\mathrm{P}_{\mathrm{N}}}, K_{\mathrm{PO}_{4}}^{\mathrm{P}_{\mathrm{D}}} \\
K_{\mathrm{NH}_{4}}^{\mathrm{P}_{\mathrm{N}}}, K_{\mathrm{NH}_{4}}^{\mathrm{P}_{\mathrm{D}}} \\
K_{\mathrm{NO}_{\mathrm{N}}}^{\mathrm{P}_{3}}, K_{\mathrm{NO}_{3}}^{\mathrm{P}_{\mathrm{D}}} \\
K_{\mathrm{Fe}}^{\mathrm{P}_{\mathrm{N}}}, K_{\mathrm{Fe}}^{\mathrm{P}_{\mathrm{D}}} \\
K_{\mathrm{Si}}^{\mathrm{P}_{\mathrm{D}}}\end{array}$ & $\begin{array}{l}0.375,0.375 \\
0.3125,5.0 \\
0.005,0.08 \\
0.5,2.5 \\
0.06,0.15 \\
1.0\end{array}$ & $\begin{array}{l}\mathrm{d}^{-1} \\
\mu \mathrm{mol} \mathrm{PL} \mathrm{P}^{-1} \\
\mu \mathrm{mol} \mathrm{N} \mathrm{L} \\
\mu \mathrm{mol} \mathrm{N} \mathrm{L} \\
\\
\mu \mathrm{mol} \mathrm{Fe} \mathrm{L}\end{array}$ & $\begin{array}{l}\text { Maximum growth rate at } 0{ }^{\circ} \mathrm{C} \\
\text { Half saturation constant for phosphate } \\
\text { Half saturation constant for ammonium } \\
\text { Half saturation constant for nitrate } \\
\text { Half saturation constant for iron } \\
\text { Half saturation constant for silicate }\end{array}$ \\
\hline
\end{tabular}

\section{Appendix B}

\section{Definition of the relative grazing rate}

We defined the specific grazing rate normalized by the phytoplankton concentration and the relative grazing ratio for each $z$ PFT $\left(\mathrm{Z}_{j}\right)$ as follows:

(Specific grazing rate $)_{\mathrm{P}_{i}}^{\mathrm{Z}_{j}}=\left(\frac{(\text { Grazing rate }) \mathrm{P}_{i}}{\mathrm{Z}_{j}}\right)$.

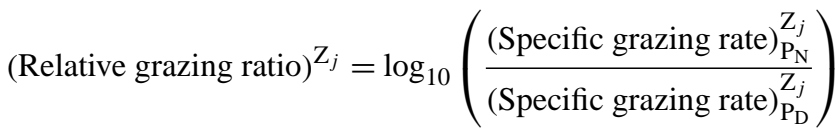

$$
=\log _{10}\left(\frac{\frac{(\text { Grazing rate }) \mathrm{Z}_{\mathrm{P}_{\mathrm{N}}}}{\left[\mathrm{P}_{\mathrm{N}}\right]}}{\frac{(\text { Grazing rate })_{\mathrm{P}_{\mathrm{D}}}}{\left[\mathrm{Z}_{\mathrm{D}}\right]}}\right) \text {. }
$$

\section{B1 PISCES and PlankTOM5}

The grazing rates by microzooplankton $\left(\mathrm{Z}_{\mathrm{Z}}\right)$ and mesozooplankton $\left(\mathrm{Z}_{\mathrm{M}}\right)$ are described as follows in PISCES and PlankTOM5:

(Total Grazing rate $)^{\mathrm{Z}_{\mathrm{Z}}}=\left(g_{\mathrm{P}_{\mathrm{N}}}^{\mathrm{Z}_{\mathrm{Z}}}+g_{\mathrm{P}_{\mathrm{D}}}^{\mathrm{Z}_{\mathrm{Z}}}+g_{\mathrm{POC}_{S}}^{\mathrm{Z}_{\mathrm{Z}}}\right)\left[\mathrm{Z}_{\mathrm{Z}}\right]$ 
Table A2. Parameters for zooplankton grazing.

\begin{tabular}{|c|c|c|c|}
\hline Parameter & Value & Unit & Description \\
\hline \multicolumn{4}{|l|}{ PISCES } \\
\hline $\begin{array}{l}G_{\max }^{\mathrm{Z}_{\mathrm{Z}}}, G_{\max }^{\mathrm{Z}_{\mathrm{M}}} \\
K_{G}^{\mathrm{Z}_{\mathrm{Z}}}, K_{G}^{\mathrm{Z}_{\mathrm{M}}} \\
\rho_{\mathrm{P}_{\mathrm{N}}}^{\mathrm{Z}_{\mathrm{Z}}}, \rho_{\mathrm{P}_{\mathrm{D}}}^{\mathrm{Z}_{\mathrm{Z}}}, \rho_{\mathrm{P}_{\mathrm{N}}}^{\mathrm{Z}_{\mathrm{M}}}, \rho_{\mathrm{P}_{\mathrm{D}}}^{\mathrm{Z}_{\mathrm{M}}} \\
\mathrm{P}_{\mathrm{D} \max }\end{array}$ & $\begin{array}{l}4.0,0.7 \\
20,20 \\
0.5,0.5 \cdot 0.2,1.0 \\
0.5\end{array}$ & $\begin{array}{l}\mathrm{d}^{-1} \\
\mu \mathrm{mol} \mathrm{CL} \mathrm{L}^{-1} \\
- \\
\mu \mathrm{mol} \mathrm{CL} \mathrm{L}^{-1}\end{array}$ & $\begin{array}{l}\text { Maximum grazing rate at } 0^{\circ} \mathrm{C} \\
\text { Half saturation constant for grazing } \\
\text { Grazing preferences } \\
\text { Maximum grazing concentration }\end{array}$ \\
\hline \multicolumn{4}{|l|}{ NEMURO } \\
\hline $\begin{array}{l}G_{\max }^{\mathrm{Z}_{\mathrm{M}} \text { on } \mathrm{P}_{\mathrm{N}}}, G_{\max }^{\mathrm{Z}_{\mathrm{M}} \text { on } \mathrm{P}_{\mathrm{D}}} \\
\lambda^{\mathrm{Z}_{\mathrm{M}}} \\
a^{\mathrm{Z}_{\mathrm{M}}}\end{array}$ & $\begin{array}{l}0.1,0.4 \\
1.4 \\
0.04\end{array}$ & $\begin{array}{l}\mathrm{d}^{-1} \\
\mu \mathrm{mol} \mathrm{N} \mathrm{L}-1 \\
\mu \mathrm{mol} \mathrm{N} \mathrm{L}\end{array}$ & $\begin{array}{l}\text { Maximum grazing rate at } 0^{\circ} \mathrm{C} \\
\text { Ivlev constant } \\
\text { Threshold value for grazing }\end{array}$ \\
\hline \multicolumn{4}{|l|}{ PlankTOM5 } \\
\hline $\begin{array}{l}G_{\max }^{\mathrm{Z}_{\mathrm{Z}}}, G_{\max }^{\mathrm{Z}_{\mathrm{M}}} \\
K_{G}^{\mathrm{Z}_{\mathrm{Z}}}, K_{G}^{\mathrm{Z}_{\mathrm{M}}} \\
p_{\mathrm{P}_{\mathrm{N}}}^{\mathrm{Z}_{\mathrm{Z}}}, p_{\mathrm{P}_{\mathrm{D}}}^{\mathrm{Z}_{\mathrm{D}}}, p_{\mathrm{P}_{\mathrm{N}}}^{\mathrm{Z}_{\mathrm{M}}}, p_{\mathrm{P}_{\mathrm{D}}}^{\mathrm{Z}_{\mathrm{M}}}\end{array}$ & $\begin{array}{l}0.92,0.3 \\
6.4,0.26 \\
1.29,0.26 .0 .51,2.54\end{array}$ & $\begin{array}{l}\mathrm{d}^{-1} \\
\mu \mathrm{mol} \mathrm{CL} \mathrm{L}^{-1} \\
-\end{array}$ & $\begin{array}{l}\text { Maximum grazing rate at } 0^{\circ} \mathrm{C} \\
\text { Half saturation constant for grazing } \\
\text { Grazing preferences }\end{array}$ \\
\hline \multicolumn{4}{|l|}{ CCSM-BEC } \\
\hline $\begin{array}{l}G_{\max }^{\mathrm{Z}_{\mathrm{GZ}} \text { on } \mathrm{P}_{\mathrm{N}}}, G_{\max }^{\mathrm{Z}_{\mathrm{GZ}} \text { on } \mathrm{P}_{\mathrm{D}}} \\
g \\
f_{\mathrm{Z}_{\mathrm{GZ}}}^{\mathrm{P}_{\mathrm{D}}}\end{array}$ & $\begin{array}{l}0.34,0.26 \\
1.05 \\
0.81\end{array}$ & $\begin{array}{l}\mathrm{d}^{-1} \\
\mu \mathrm{mol} \mathrm{CL} \mathrm{L}^{-1} \\
-\end{array}$ & $\begin{array}{l}\text { Maximum grazing rate at } 0^{\circ} \mathrm{C} \\
\text { Half saturation constant for grazing } \\
\text { Scaling factor for grazing on diatoms }\end{array}$ \\
\hline
\end{tabular}

(Total Grazing rate $)^{\mathrm{Z}_{\mathrm{M}}}=\left(g_{\mathrm{P}_{\mathrm{N}}}^{\mathrm{Z}_{\mathrm{M}}}+g_{\mathrm{P}_{\mathrm{D}}}^{\mathrm{Z}_{\mathrm{M}}}+g_{\mathrm{Z}_{\mathrm{Z}}}^{\mathrm{Z}_{\mathrm{M}}}+g_{\mathrm{POC}_{S}}^{\mathrm{Z}_{\mathrm{M}}}+g_{\mathrm{POC}_{b}}^{\mathrm{Z}_{\mathrm{M}}}\right)\left[\mathrm{Z}_{\mathrm{M}}\right]$

$g_{\mathrm{P}_{i}}^{\mathrm{Z}_{j}}$ are specific grazing rates on a resource, $i$, each zooplankton can graze on.

$g_{\mathrm{P}_{i}}^{\mathrm{Z}_{j}}=G_{\max }^{\mathrm{Z}_{j}} f\left(T_{\mathrm{dep}}\right) \frac{p_{\mathrm{P}_{i}}^{\mathrm{Z}_{j}}\left[\mathrm{P}_{i}\right]}{K^{\mathrm{Z}_{j}}+\sum_{I}\left(p_{\mathrm{P}_{I}}^{\mathrm{Z}_{j}}\left[\mathrm{P}_{I}\right]\right)}$,

where $G_{\max }^{\mathrm{Z}_{j}}$ are the maximum grazing rates, $f\left(T_{\mathrm{dep}}\right)$ is a temperature dependency term, and $K^{\mathrm{Z}_{j}}$ are the half saturation constants for grazing. $I$ denotes all the resources each zooplankton can graze on. $p_{\mathrm{P}_{i}}^{\mathrm{Z}_{j}}$ are coefficients for grazing preferences for a resource $i$, and given as constants in PlankTOM5 (Table A2). In PISCES, $p_{\mathrm{P}_{i}}^{\mathrm{Z}_{j}}$ are functions of grazing preferences $\rho_{\mathrm{P}_{i}}^{\mathrm{Z}_{j}}$ (Table A2).

$p_{\mathrm{P}_{i}}^{\mathrm{Z}_{j}}=\frac{\rho_{\mathrm{P}_{i}}^{\mathrm{Z}_{j}}}{\sum_{I} \rho_{\mathrm{P}_{I}}^{\mathrm{Z}_{j}}}$
The relative grazing ratio is represented as follows;

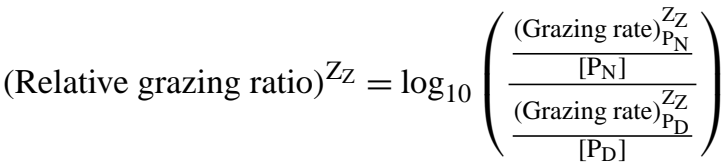

$=\log _{10}\left(\frac{\frac{g_{\mathrm{P}_{\mathrm{N}}}^{\left.\mathrm{Z}_{\mathrm{Z}}\right]}}{\left[\mathrm{P}_{\mathrm{N}}\right]}}{\frac{g_{\mathrm{P}_{\mathrm{D}}}^{\left.\mathrm{Z}_{\mathrm{Z}}\right]}}{\left[\mathrm{P}_{\mathrm{D}}\right]}}\right)$

$=\log _{10}\left(\frac{p_{\mathrm{P}_{\mathrm{N}}}^{\mathrm{Z}_{\mathrm{Z}}}}{p_{\mathrm{P}_{\mathrm{D}}}^{\mathrm{Z}_{\mathrm{Z}}}}\right)$ in PlankTOM5,

$=\log _{10}\left(\frac{\rho_{\mathrm{P}_{\mathrm{N}}}^{\mathrm{Z}_{\mathrm{Z}}}}{\rho_{\mathrm{P}_{\mathrm{D}}}^{\mathrm{Z}_{\mathrm{Z}}} \frac{\rho_{\left.\min \left(\mathrm{P}_{\mathrm{Dmax}}, \mathrm{P}_{\mathrm{D}}\right)\right]}}{\left[\mathrm{P}_{\mathrm{D}}\right]}}\right)$ in PISCES.

$\mathrm{P}_{\mathrm{Dmax}}$ is the maximum grazing concentration for diatoms by microzooplankton in PISCES, and given as constants (Table A2).

(Relative grazing ratio) $^{\mathrm{Z}_{\mathrm{M}}}=\log _{10}\left(\frac{p_{\mathrm{P}_{\mathrm{N}}}^{\mathrm{Z}_{\mathrm{M}}}}{p_{\mathrm{P}_{\mathrm{D}}}^{\mathrm{Z}_{\mathrm{M}}}}\right)$

in PlankTOM5,

$=\log _{10}\left(\frac{\rho_{\mathrm{P}_{\mathrm{M}}}^{\mathrm{Z}_{\mathrm{M}}}}{\rho_{\mathrm{P}_{\mathrm{D}}}^{\mathrm{Z}_{\mathrm{M}}}}\right)$ in PISCES. 


\section{B2 NEMURO}

The grazing rates of mesozooplankton on nanophytoplankton and diatoms are described as follows:

$$
\begin{aligned}
(\text { Grazing rate }){ }_{\mathrm{P}_{\mathrm{N}}}^{\mathrm{Z}_{\mathrm{M}}}= & G_{\max }^{\mathrm{Z}_{\mathrm{M}} \text { on } \mathrm{P}_{\mathrm{N}}} f\left(T_{\mathrm{dep}}\right) \\
& \left(1-\exp \left(\lambda^{\mathrm{Z}_{\mathrm{M}}}\left(a^{\mathrm{Z}_{\mathrm{M}}}-\left[\mathrm{P}_{\mathrm{D}}\right]\right)\right)\right)\left[\mathrm{Z}_{\mathrm{M}}\right]
\end{aligned}
$$

(Grazing rate $)_{\mathrm{P}_{\mathrm{D}}}^{\mathrm{Z}_{\mathrm{M}}}=G_{\max }^{\mathrm{Z}_{\mathrm{M}} \text { on } \mathrm{P}_{\mathrm{D}}} f\left(T_{\mathrm{dep}}\right)$

$$
\left(1-\exp \left(\lambda^{\mathrm{Z}_{\mathrm{M}}}\left(a^{\mathrm{Z}_{\mathrm{M}}}-\left[\mathrm{P}_{\mathrm{D}}\right]\right)\right)\right)\left[\mathrm{Z}_{\mathrm{M}}\right],(\mathrm{B} 12)
$$

where $G_{\max }^{\mathrm{Z}_{\mathrm{M}} \text { on } \mathrm{P}_{\mathrm{N}}}$ and $G_{\max }^{\mathrm{Z}_{\mathrm{M}} \text { on } \mathrm{P}_{\mathrm{D}}}$ are the maximum grazing rates of mesozooplankton on nanophytoplankton and diatoms. $\lambda^{\mathrm{Z}_{\mathrm{M}}}$ and $a^{\mathrm{Z}_{\mathrm{M}}}$ are the coefficients of the Ivlev equation. Then, the relative grazing ratio is represented as follows:

(Relative grazing ratio) ${ }^{Z_{M}}$

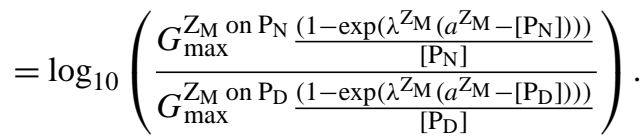

Microzooplankton graze only on nanophytoplankton, and macrozooplankton graze only on diatoms.

\section{B3 CCSM-BEC}

The grazing rates of generic zooplankton on nanophytoplankton and diatoms are described as follows:

$$
\begin{aligned}
(\text { Grazing Rate })_{\mathrm{P}_{\mathrm{N}}}^{\mathrm{Z}_{\mathrm{GZ}}}= & G_{\mathrm{max}}^{\mathrm{Z}_{\mathrm{GZ}} \text { on } \mathrm{P}_{\mathrm{N}}} f\left(T_{\mathrm{dep}}\right) \\
& \left(\frac{\left[\mathrm{P}_{\mathrm{N}}\right]^{2}}{g^{2}+\left[\mathrm{P}_{\mathrm{N}}\right]^{2}}\right)\left[\mathrm{Z}_{\mathrm{GZ}}\right],
\end{aligned}
$$

$(\text { Grazing Rate })_{\mathrm{P}_{\mathrm{D}}}^{\mathrm{Z}_{\mathrm{DZ}}}=G_{\max }^{\mathrm{Z}_{\mathrm{GZ}}}$ on $\mathrm{P}_{\mathrm{D}} f\left(T_{\mathrm{dep}}\right)$

$$
\left(\frac{\left[\mathrm{P}_{\mathrm{D}}\right]^{2}}{g^{2} f_{\mathrm{Z}_{\mathrm{GZ}}}^{\mathrm{P}_{\mathrm{D}}}+\left[\mathrm{P}_{\mathrm{D}}\right]^{2}}\right)\left[\mathrm{Z}_{\mathrm{GZ}}\right]
$$

where $\mathrm{Z}_{\mathrm{GZ}}$ represents the generic zooplankton, $G_{\max }^{\mathrm{Z}_{\mathrm{GZ}}}$ on $\mathrm{P}_{\mathrm{N}}$ and $G_{\max }^{Z_{\mathrm{GZ}} \text { on } \mathrm{P}_{\mathrm{D}}}$ are the maximum grazing rates of generic zooplankton on nanophytoplankton and diatoms. $g$ is a grazing coefficient and $f_{\mathrm{Z}_{\mathrm{GZ}}}^{\mathrm{P}_{\mathrm{D}}}$ is a scaling factor for the grazing on diatoms. Then the relative grazing ratio is represented as follows:

$$
\begin{aligned}
& \text { (Relative Grazing Ratio) }{ }^{\mathrm{Z}_{\mathrm{GZ}}}
\end{aligned}
$$

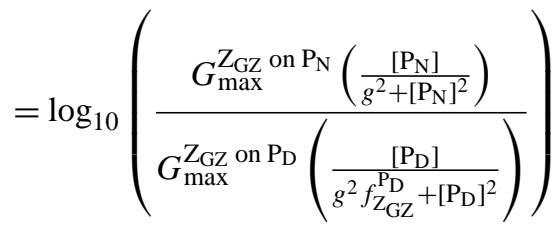

Acknowledgements. T. Hashioka, Y. Yamanaka and T. Hirata, were supported by the Grant-in-Aid for the Global COE Program from MEXT, by the Global Environment Research Fund (S-5) from the Ministry of the Environment and by the Strategic Young Researcher Overseas Visits Program for Accelerating Brain Circulation from JSPS. S. Doney, I. Lima and S. Sailley acknowledge support from C-MORE (NSF EF-0424599).

Edited by: G. Herndl

\section{References}

Aita, M. N., Yamanaka, Y., and Kishi, M. J.: Effects of ontogenetic vertical migration of zooplankton on annual primary production - using NEMURO embedded in a general circulation model, Fish. Oceanogr., 12, 284-290, 2003.

Aita, M. N., Yamanaka, Y., and Kishi, M. J.: Interdecadal variation of the lower trophic ecosystem in the North Pacific between 1948 and 2002, in a 3-D implementation of the NEMURO model, Ecol. Model., 202, 381-394, doi:10.1016/j.ecolmodel.2006.07.045, 2007.

Alvain, S., Moulin, C., Dandonneau, Y., and Bréon, F. M.: Remote sensing of phytoplankton groups in case 1 waters from global SeaWiFS imagery, Deep Sea Res. Pt. I, 52, 1989-2004, 2005.

Alvain, S., Moulin, C., Dandonneau, Y., and Loisel, H.: Seasonal distribution and succession of dominant phytoplankton groups in the global ocean: A satellite view, Global Biogeochem. Cy., 22, GB3001, doi:10.1029/2007GB003154, 2008.

Alvain, S., Loisel, H., and Dessailly, D.: Theoretical analysis of ocean color radiances anomalies and implications for phytoplankton groups detection in case 1 waters, Opt. Express, 20, 1070-1083, 2012.

Aumont, O. and Bopp, L.: Globalizing results from ocean in situ iron fertilization studies, Global Biogeochem. Cy., 20, 1-15, 2006.

Blasco, D., Packard, T. T., and Garfield, P. C.: Size dependence of growth rate, respiratory electron transport system activity and chemical composition in marine diatoms in the laboratory, J. Phycol., 18, 58-63, 1982.

Bopp, L., Aumont, O., Cadule, P., Alvain, S., and Gehlen, M.: Response of diatoms distribution to global warming and potential implications: A global model study, Geophys. Res. Lett., 32, L19606, doi:10.1029/2005GL023653, 2005.

Boyd, P. W. and Doney, S. C.: Modelling regional responses by marine pelagic ecosystems to global climate change, Geophys. Res. Lett., 29, 1806, doi:10.1029/2001GL014130, 2001.

Buitenhuis, E. T., Le Quéré, C., Aumont, O., Beaugrand, G., Bunker, A., Hirst, A., Ikeda, T., O’Brien, T., Piontkovski S., and Straile, D.: Biogeochemical fluxes mediated by mesozooplankton, Global Biogeochem. Cy., 20, GB2003, doi:10.1029/2005GB002511, 2006.

Buitenhuis, E., Rivkin, R., Sailley, S., and Le Quéré C.: Biogeochemical fluxes through microzooplankton, Global Biogeochem. Cy., 24, GB4015, doi:10.1029/2009GB003601, 2010.

Chisholm, S. W.: What limits phytoplankton growth, Oceanus, 35, 36-46, 1992

Denman, K. L., Brasseur, G., Chidthaisong, A., Ciais, P., Cox, P. M., Dickinson, R. E., Hauglustaine, D., Heinze, C., Holland, E., Jacob, D., Lohmann, U., Ramachandran, S., da Silva Dias, P. L., 
Wofsy, S. C., and Zhang, X.: Couplings Between Changes in the Climate System and Biogeochemistry, in: Climate Change 2007: The Physical Science Basis. Contribution of Working Group I to the Fourth Assessment Report of the Intergovernmental Panel on Climate Change, edited by: Solomon, S., Qin, D., Manning, M., Chen, Z., Marquis, M., Averyt, K. B., Tignor, M., and Miller, H. L., Cambridge University Press, Cambridge, UK and New York, NY, USA, 2007.

Eppley, R. W. and Sloan, P. R.: Growth rates of marine phytoplankton: correlation with light absorption by cell chlorophyll-a, Physiol. Plantarum, 19, 47-59, 1966.

Eppley, R.: Temperature and phytoplankton growth in the sea, Fish. Bull., 70, 1063-1085, 1972.

ESSD special issue: MAREDAT - Towards a world atlas of marine plankton functional types, edited by: W. Smith and S. Pesant, http://www.earth-syst-sci-data-discuss.net/special_issue9. html, 2012.

Falkowski, P. G.: Ecosystem function and biogeochemical cycles: the role of the phytoplankton, US JGOFS Newsletter, June 1999, 4-5, 1999.

Finkel, Z. V., Beardall, J., Flynn, K. J., Quigg, A., Rees, T. A. V., and Raven, J. A.: Phytoplankton in a changing world: cell size andelemental stoichiometry, J. Plankton. Res., 32, 119-137, doi:10.1093/plankt/fbp098, 2010.

Geider, R. J., MacIntyre H. L., and Kana, T. M.: A dynamic regulatory model of phytoplankton acclimation to light, nutrients and temperature, Limnol. Oceanogr., 43, 679-694, 1998.

Hashioka, T. and Yamanaka, Y.: Ecosystem change in the western North Pacific associated with global warming obtained by 3-D NEMURO, Ecol. Model., 202, 95-104, doi:10.1016/j.ecolmodel.2006.05.038, 2007a.

Hashioka, T. and Yamanaka, Y.: Seasonal and regional variations of phytoplankton groups by top-down and bottom-up controls obtained by a 3-D ecosystem model, Ecol. Model., 202, 68-80, doi:10.1016/j.ecolmodel.2005.12.002, 2007b.

Hashioka, T., Sakamoto, T. T., and Yamanaka, Y.: Potential impact of global warming on North Pacific spring blooms projected by an eddy-permitting 3-D ocean ecosystem model, Geophys. Res. Lett., 36, L20604, doi:10.1029/2009GL038912, 2009.

Hasumi, H.: CCSR Ocean Component Model (COCO) Version 4.0, CCSR report No. 25, 103 pp., 2006.

Hirata, T., Hardman-Mountford, N. J., Brewin, R. J. W., Aiken, J., Barlow, R., Suzuki, K., Isada, T., Howell, E., Hashioka, T., Noguchi-Aita, M., and Yamanaka, Y.: Synoptic relationships between surface Chlorophyll-a and diagnostic pigments specific to phytoplankton functional types, Biogeosciences, 8, 311-327, doi:10.5194/bg-8-311-2011, 2011

Ivlev, V. S.: Experimental ecology of the feeding of fishes, Yale University Press (1961), 1955.

Ivleva, I. V.: The dependence of crustacean respiration rate on body mass and habitat temperature, Int. Rev. Ges. Hydrobio., 65, 1-47, 1980.

Kishi, M. J., Kashiwai, M., Ware, D. M., Megrey, B. A., Eslinger, D. L., Werner, F. E., Aita, M. N., Azumaya, T., Fujii, M., Hashimoto, S., Huang, D., Iizumi, H., Ishida, Y., Kang, S., Kantakov, G. A., Kim, H.-C., Komatsu, K., Navrotsky, V. V., Smith, S. L., Tadokoro, K., Tsuda, A., Yamamura, O., Yamanaka, Y., Yokouchi, K., Yoshie, N., Zhang, J., Zuenko Y. I., and Zvanlinsky, V. I.: NEMURO - introduction to a lower trophic level model for the North Pacific marine ecosystem, Ecol. Model., 202 , 1225, 2007.

Kudo, I., Miyamoto, M., Noiri, Y., and Maita, Y.: Combined effect of temperature and iron on the growth and physiology of the marine diatom Pheodactylum tricornutum (Bacillario-phyceae), J. Phycol., 36, 1096-1102, 2000.

Le Quéré, C., Harrison, S. P., Colin Prentice, I., Buitenhuis, E. T., Aumont, O., Bopp, L., Claustre, H., Cotrim da Cunha, L., Geider, R., Giraud, X., Klaas, C., Kohfeld, K. E., Legendre, L., Manizza, M., Platt, T., Rivkin, R. B., Sathyendranath, S., Uitz, J., Watson, A. J., and Wolf-Gladrow, D.: Ecosystem dynamics based on plankton functional types for global ocean biogeochemistry models, Glob. Change Biol., 11, 2016-2040, doi:10.1111/j.13652486.2005.1004.x, 2005.

Mackas D. L. and Tsuda, A.: Mesozooplankton in the eastern and western subarctic Pacific: community structure, seasonal life histories, and interannual variability, Prog. Oceanogr., 43, 335-363, doi:10.1016/S0079-6611(99)00012-9, 1999.

Madec, G., Delecluse, P., Imbard, M., and Levy, C.: OPA 8.1 ocean general circulation model reference manual, Note du Pole de modélisation, Institut Pierre Simon Laplace (IPSL), France, No. 11, 91 pp., 1998.

Manizza, M., Le Quéré, C., and Buitenhuis, E.: Sensitivity of global ocean biogeochemical dynamics to ecosystem structure in a future climate, Geophys. Res. Lett., 37, L13607, doi:10.1029/2010GL043360, 2010.

Mann, D. G.: The species concept in diatoms, Phycologia, 38, 437495, 1999.

Martin, J., Raibaud, A., and Ollo, R.: Terminal pattern elements in Drosophila embryo induced by the Torso-like protein, Nature, 367, 741-745, 1994.

Michaelis, L. and Menten, M.: Die kinetik der invertinwirkung, Biochemistry Zeitung, 49, 333-369, 1913.

Milligan, A. J. and Harrison, P. J.: Effects of non-steady-state iron limitation on nitrogen assimilatory enzymes in the marine diatom Thalassiosira weissflogii(Bacillariophyceae), J. Phycol., 36, 78$86,2000$.

Moore, J. K., Doney, S. C., and Lindsay, K.: Upper ocean ecosystem dynamics and iron cycling in a global threedimensional model, Global Biogeochem. Cy., 18, GB4028, doi:10.1029/2004GB002220, 2004.

Moriarty, R.: The role of macro-zooplankton in the global carbon cycle, Ph.D. dissertation, University of East Anglia, 2009.

Nelson, D.M., Tréguer, P., Brzezinski, M. A., Leynaert, A., and Quéguiner, B.: Production and dissolution of biogenic silica in the ocean. Revised global estimates, comparison with regional data and relationship to biogenic sedimentation, Global Biogeochem. Cy., 9, 359-372, 1995.

Pondaven, P., Fravalo, C., Ruiz-Pino, D., Treguer, P., Queguiner, B., and Jeandel, C.: Modelling the silica pump in the Permanently Open Ocean Zone of the Southern Ocean, J. Marine Syst., 17, 587-619, 1998.

Sailley, S., Vogt, M., Doney, S. C., Aita M. N., Bopp, L., Buitenhuis, E. T., Hashioka, T., Lima, I., Le Quéré, C., and Yamanaka, Y: Comparing food web structures and dynamics across a suite of global marine ecosystem models. Ecol. Model., 261, 43-57 doi:10.1016/j.ecolmodel.2013.04.006, 2013. 
Sarthou, G., Timmermans, K. R., Blain, S., and Treguer, P.: Growth physiology and fate of diatoms in the ocean: a review, J. Sea Res., 53, 25-42, 2005.

Schone, H. K.:. The influence of light and temperature on the growth rates of six phytoplankton species from the upwelling area off northwest Africa, Rapp. P.-V. Reun. Cons. Int. Explor. Mer., 180, 246-253, 1982.

Smetacek, V.: Diatoms and the ocean carbon cycle, Protist, 150, 25-32, 1999.

Steele, J. H.: Environmental control of photosynthesis in the sea, Limnol. Oceanogr., 7, 137-172, 1962.

Steinacher, M., Joos, F., Frölicher, T. L., Bopp, L., Cadule, P., Cocco, V., Doney, S. C., Gehlen, M., Lindsay, K., Moore, J. K., Schneider, B., and Segschneider, J.: Projected 21st century decrease in marine productivity: a multi-model analysis, Biogeosciences, 7, 979-1005, doi:10.5194/bg-7-979-2010, 2010.

Tang, E. P. Y.: The allometry of algal growth rates, J. Plankton Res. 17, 1325-1335, 1995.

Tréguer, P. and Pondaven, P.: Silica control of carbon dioxide, Nature, 406, 358-359, 2000.
Vogt, M., Hashioka, T., Payne, M., Buitenhuis, E. T., Le Quere, C., Alvain, S., Aita, M. N., Bopp, L., Doney, S. C., Hirata, T., Lima, I., Sailley, S., and Yamanaka, Y.: The distribution, dominance patterns and ecological niches of plankton functional types in Dynamic Green Ocean Models and satellite estimates, Biogeosciences Discuss., in press, 2013

Ward, B. A., Dutkiewicz, S., Jahn, O., and Follows, M. J.: A size-structured food-web model for the global ocean, Limnol. Oceanogr., 57, 1877-1891, 2012.

Williams, R. B.: Division rates of salt marsh diatoms in relation to salinity and cell size, Ecology, 45, 877-880, 1964.

Wroblewski, J. S.: A model of phytoplankton plume formation during variable Oregon upwelling, J. Mar. Res., 35, 357-394, 1977.

Yamanaka, Y., Yoshie, N., Fujii, M., Aita, M. N., and Kishi, M. J.: An ecosystem model coupled with nitrogen-silicon-carbon cycles applied to Station A7 in the northwestern Pacific, J. Oceanogr., 60, 227-241, 2004. 